\title{
An automated dynamic chamber system for surface exchange measurement of non-reactive and reactive trace gases of grassland ecosystems
}

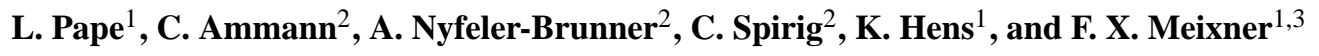 \\ ${ }^{1}$ Max Planck Institute for Chemistry, Biogeochemistry Department, P.O. Box 3060, 55020 Mainz, Germany \\ ${ }^{2}$ Agroscope ART Research Station, Reckenholzstrasse 191, 8046 Zürich, Switzerland \\ ${ }^{3}$ Department of Physics, University of Zimbabwe, P.O. Box MP 167, Harare, Zimbabwe
}

Received: 27 June 2008 - Published in Biogeosciences Discuss.: 12 August 2008

Revised: 27 January 2009 - Accepted: 27 January 2009 - Published: 18 March 2009

\begin{abstract}
We present an automated dynamic chamber system which is optimised for continuous unattended flux measurements of multiple non-reactive and reactive trace gases on grassland ecosystems. Main design features of our system are (a) highly transparent chamber walls consisting of chemically inert material, (b) individual purging flow units for each chamber, and (c) a movable lid for automated opening and closing of the chamber. The purging flow rate was chosen high enough to keep the mean residence time of the chamber air below one minute. This guarantees a proven efficient mixing of the chamber volume and a fast equilibration after lid closing. The dynamic chamber system is able to measure emission as well as deposition fluxes of trace gases. For the latter case, the modification of the turbulent transport by the chamber (compared to undisturbed ambient conditions) is quantitatively described by a bulk resistance concept.
\end{abstract}

Beside a detailed description of the design and functioning of the system, results of field applications at two grassland sites are presented. In the first experiment, fluxes of five trace gases $\left(\mathrm{CO}_{2}, \mathrm{H}_{2} \mathrm{O}, \mathrm{NO}, \mathrm{NO}_{2}, \mathrm{O}_{3}\right)$ were measured simultaneously on small grassland plots. It showed that the dynamic chamber system is able to detect the characteristic diurnal cycles with a sufficient temporal resolution. The results also demonstrated the importance of considering the chemical source/sink in the chamber due to gas phase reactions for the reactive compounds of the $\mathrm{NO}-\mathrm{NO}_{2}-\mathrm{O}_{3}$ triad. In a second field experiment,

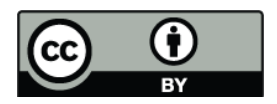

Correspondence to: L. Pape

(llehmann@mpch-mainz.mpg.de) chamber flux measurements of $\mathrm{CO}_{2}$ and methanol were compared to simultaneous independent eddy covariance flux measurements on the field scale. The fluxes obtained with the two methods showed a very good agreement indicating a minimal disturbance of the chambers on the physiological activity of the enclosed vegetation.

\section{Introduction}

Grassland ecosystems cover a large fraction $(21 \%)$ of the global terrestrial surface (Butcher et al., 1992). They are sources and sinks for numerous non-reactive (e.g. $\mathrm{CO}_{2}, \mathrm{~N}_{2} \mathrm{O}, \mathrm{CH}_{4}$ ) and reactive (e.g. $\mathrm{NO}, \mathrm{NO}_{2}, \mathrm{NH}_{3}$, $\mathrm{O}_{3}$, VOC) trace gases which play an important role in atmospheric chemistry and air pollution (Brunner et al., 2007a; Bassin et al., 2007; Tilsner et al., 2003; Herrmann et al., 2001). Grassland ecosystems are characterised by distinct dynamics with respect to vegetation growth, species diversity, and management effects. Therefore, trace gas emission from grassland is highly variable (diurnal, seasonal) and often event related, e.g. pulse-like emissions following fertilisation, cut, rain, blooming, etc. (e.g. Bakwin et al., 1990; Davison et al., 2008; Meixner et al., 1997).

Grassland vegetation is delicate and may easily be affected by measurement installations. Furthermore, it may undergo several management activities which require periodical removal of field installations. Therefore, the ideal flux measurement setup for grassland should be robust and mobile. It should facilitate automated (quasi-) continuous measurements at multiple points or sub-plots to capture diurnal and seasonal variations as well as spatial variability

Published by Copernicus Publications on behalf of the European Geosciences Union. 
(on large fields) or management effects (on small parallel plots). The disturbance of environmental conditions (e.g. radiation, temperature, humidity, trace gas concentrations) by measurement installations should be minimised in order to ensure optimum vegetation development and plant physiological activity. This is particularly important for flux measurement of those trace gases whose exchange process is predominantly controlled by plant stomatal activity. Micrometeorological methods (e.g. eddy covariance methods) are optimal concerning minimal disturbance. However, they are limited to large fields (with extensions of typically $\geq 100 \mathrm{~m}$; see Horst and Weil, 1994) and to few trace gases for which fast (time response of $1 \mathrm{~Hz}$ or higher) and very sensitive sensors are available. For smaller plots (usually used for manipulation experiments), chamber methods are the main alternative to micrometeorological techniques. One chamber typically covers a surface area of 0.01 to $1 \mathrm{~m}^{2}$ (Livingston and Hutchinson, 1995). Using multiple spatially distributed chambers, the flux variability (heterogeneity) of larger field areas can be assessed. Static (i.e. closed, non-stationary) chambers are widely used for flux measurements of greenhouse gases or other inert trace gases (see e.g. Pumpanen et al., 2004). However, during the closed state (measurement phase) they usually cause non-constant environmental conditions inside the chamber which may be far away from ambient conditions (e.g. accumulation of heat and water vapour; strong depletion of $\mathrm{CO}_{2}$ and other depositing trace gases). Thus, static chambers can considerably affect plant activity and consequently the emission or uptake processes of the trace gases of interest. The non-stationary conditions inside the chamber cause additional problems for reactive gases, because the influence of chemical sources or sinks is not constant and thus difficult to quantify.

For measuring the surface exchange of reactive trace gases, dynamic (i.e. steady-state, flow-through) chambers are more suitable (Meixner, 1994). Continuous renewal of the chamber air guarantees that trace gas concentrations and other related quantities remain (quasi-) constant and close to ambient conditions. The design and operation characteristics of dynamic chambers reported so far were usually adjusted to the requirements of a specific trace gas and focussed on either plant-air or soil-air exchange. Many of the chambers were operated manually and thus could only be applied in the field during intensive short campaigns or with a very low time resolution (in the order of weeks).

In this paper we present an automated dynamic chamber system which is optimised for continuous unattended flux measurements of multiple non-reactive and reactive trace gases on grassland ecosystems. The development of this system is based on previous (partly automated) systems used for $\mathrm{NO}, \mathrm{NO}_{2}$, and $\mathrm{O}_{3}$ exchange of marshland, heath, and wheat fields (Remde et al., 1993; Ludwig, 1994; Meixner, 1994) and forest soil (Gut et al., 2002a, b; Lehmann, 2002), as well as for the reactive organic trace gas exchange of tree branches (Kesselmeier et al., 1997; Kuhn et al., 2002). Main features of our system are (a) highly transparent chamber walls consisting of chemically inert material to minimise wall loss of reactive trace gases, (b) individual purging flow units for each chamber, and (c) an automated lid so that the chamber can be kept open except for the short measurement periods. Beside a detailed description of the design and functioning of the system, we will present results of specific test measurements, and exemplary results of field applications of our system at two different grassland sites.

\section{Materials and methods}

\subsection{Dynamic chamber theory}

\subsubsection{Chamber flux of inert trace gases}

For any chamber system, the flux $F_{\text {cham }}$ of an inert trace gas (i.e. no chemical reactions with other air constituents or with the chamber walls) between the plant-soil system and the chamber air is determined by the mass balance of the trace gas in the enclosed headspace. As derived in Appendix B, it can be described as:

$$
V \times \rho_{\mathrm{d}} \frac{d \mu_{\text {cham }}}{d t}=A \times F_{\text {cham }}-Q \times \rho_{\mathrm{d}}\left[\mu_{\text {cham }}-\mu_{\mathrm{amb}}\right]
$$

Here $V$ denotes the volume and $A$ the soil surface area enclosed by the chamber, and $Q$ is the purging air flow rate. $\mu_{\text {cham }}$ and $\mu_{\mathrm{amb}}$ are the trace gas mixing ratios of the inflowing ambient air and of the outflowing chamber air, respectively (see Fig. 1a). $\rho_{\mathrm{d}}$ is the density of the dry air molecules, and $t$ denotes time. A complete list of symbols, abbreviations, and units is given in Appendix A. While for static chambers $Q$ is zero, dynamic chambers are operated with a continuous purging of the chamber air. In this way, a dynamic equilibrium (steady-state) is developing, where the time derivative and time dependences in Eq. (1) vanish. Under equilibrium conditions, the mass budget equation for a dynamic chamber can thus be reduced and rearranged to:

$F_{\text {cham }}=\frac{Q}{A} \times \rho_{\mathrm{d}}\left[\mu_{\mathrm{cham}}-\mu_{\mathrm{amb}}\right]$

Realisation of the dynamic chamber principle commonly follows some general assumptions and design features. Since the purging air flow $(Q)$ through the chamber has to be known for the flux determination, it is usually produced and maintained constant by a pump or fan either at the inlet or at the outlet. With a sufficiently high purging air flow and/or with the help of additional internal mixing fans (see Sect. 2.2), the chamber headspace can be assumed to be well mixed, i.e. the trace gas mixing ratio $\left(\mu_{\text {cham }}\right)$ is uniform throughout the chamber and thus equals the mixing ratio of the out-flowing air (as already assumed in Eq. 1). 
(a)

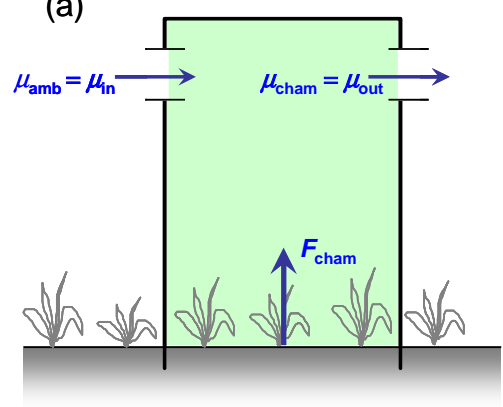

(b)

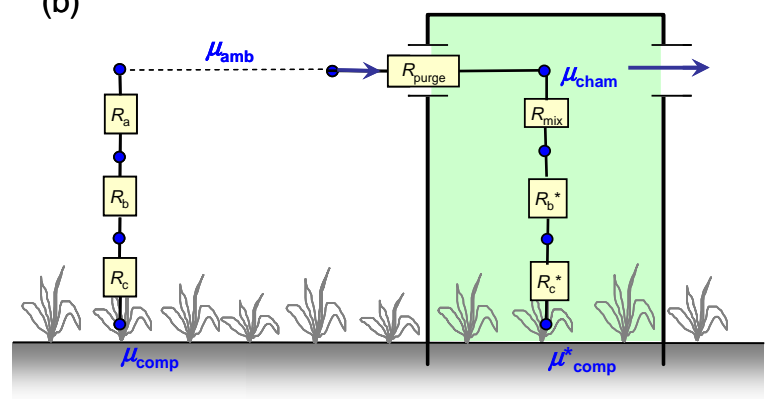

Fig. 1. (a) Schematic design of a dynamic chamber for measuring a trace gas flux $F_{\text {cham }}$ according to Eqs. (2) or (11); (b) Schematic bulk resistance model for the trace gas transfer between the ambient air at the chamber inlet and the soil-vegetation system in undisturbed conditions (left, see Eq. 3) and with the application of a dynamic chamber purged with ambient air (right, see Eq. 4).

\subsubsection{Modification of turbulent transport by the chamber}

As the most important characteristic of a dynamic chamber, the measured trace gas exchange should be as representative as possible, i.e. not affected (altered) by the application of the chamber itself. However, the alteration of the aerodynamic transport is an inherent unavoidable consequence of the application of dynamic chambers. Hence, trace gas concen-trations above and within the enclosed vegetation canopy are modified. In order to describe this effect in a quantitative way, we consider the common bulk resistance model (Hicks et al., 1987; Wesely and Hicks, 2000) and adjust it for the specific environment of the chamber volume. As shown in Fig. 1b, the total exchange resistance under ambient conditions outside the chamber consists of the sum of the turbulent resistance $\left(R_{\mathrm{a}}\right)$, the quasi-laminar boundary layer resistance $\left(R_{\mathrm{b}}\right)$, and the surface resistance $\left(R_{\mathrm{c}}\right)$. Thus the true trace gas flux in ambient conditions $\left(F_{\mathrm{amb}}\right)$ without the influence of a chamber can be written as:

$F_{\mathrm{amb}}=\frac{1}{R_{\mathrm{a}}+R_{\mathrm{b}}+R_{\mathrm{c}}} \rho_{\mathrm{d}}\left(\mu_{\mathrm{comp}}-\mu_{\mathrm{amb}}\right)$

The so-called "compensation point" (Wesely and Hicks, $2000)$ or "compensation mixing ratio" $\left(\mu_{\text {comp }}\right)$ represents a real or virtual concentration at the lower end of the resistance chain, i.e. inside the plant leaf or in the soil (for microbiological meaning of $\mu_{\text {comp }}$ see Conrad, 1994). For exclusively deposited compounds like $\mathrm{O}_{3}$ or nitric acid $\left(\mathrm{HNO}_{3}\right), \mu_{\text {comp }}$ equals zero.

The application of the dynamic chamber modifies the turbulence regime and thus the resistance chain for the trace gas exchange between the ambient air and the plant/soil system (see right-hand part of Fig. 1b). The most obvious modification happens to $R_{\mathrm{a}}$. It is replaced by two resistances in series, namely the purging resistance $\left(R_{\text {purge }}\right)$ between ambient and chamber air and the mixing resistance $\left(R_{\text {mix }}\right)$, which represents the turbulent mixing inside the chamber. If the chamber air is reasonably well mixed by fans, $R_{\text {mix }}$ gets very small as shown by Ludwig (1994). The forced mixing inside the chamber also results in a modified boundary layer resistance $R_{\mathrm{b}}^{*}$ as compared to $R_{\mathrm{b}}$ outside of the chamber.

As mentioned above, a fundamental requirement for the dynamic chamber technique is minimum alteration of the investigated source/sink processes of the trace gas of interest within plants and soil by the application of the chamber itself. If this requirement is fulfilled by an optimised chamber design (see below), the chamber compensation mixing ratio $\left(\mu_{\mathrm{comp}}^{*}\right)$ and the chamber surface resistance $\left(R_{\mathrm{c}}^{*}\right)$ should be very close to the conditions outside of the chamber (i.e. $\mu_{\text {comp }}^{*} \approx \mu_{\text {comp }}$ and $R_{\mathrm{c}}^{*} \approx R_{\mathrm{c}}$ ), despite the modified aerodynamic transport regime. In analogy to Eq. (3), the chamber flux can be written as:

$F_{\text {cham }}=\frac{1}{R_{\text {purge }}+R_{\text {mix }}+R_{\mathrm{b}}^{*}+R_{\mathrm{c}}} \rho_{\mathrm{d}}\left(\mu_{\text {comp }}-\mu_{\mathrm{amb}}\right)$

For depositing compounds with zero or low compensation points $\left(\mu_{\text {comp }} \ll \mu_{\mathrm{amb}}\right), F_{\text {cham }}$ is generally affected by the modified transport through the chamber. The magnitude and direction of the modification strongly depends on the relative size of $R_{\mathrm{c}}$ and the turbulence related resistances. This can be elucidated by the ratio of $F_{\text {cham }}$ and $F_{\text {amb }}$ following from Eqs. (3) and (4):

$$
\frac{F_{\text {cham }}}{F_{\text {amb }}}=\frac{R_{\mathrm{a}}+R_{\mathrm{b}}+R_{\mathrm{c}}}{R_{\text {purge }}+R_{\text {mix }}+R_{\mathrm{b}}^{*}+R_{\mathrm{c}}}
$$

In non-modified ambient conditions, $R_{\mathrm{a}}$ and $R_{\mathrm{b}}$ are determined by the turbulence intensity and can be described as functions of the friction velocity $u_{*}$ and the thermal stability (Hicks et al., 1987). In this way, the measured chamber flux determined by Eq. (2) can be corrected if all resistance values inside and outside the chamber can be quantified.

In the case of trace gas emissions (e.g. for NO and most VOCs), the underlying production processes in the soil and plants are usually independent of the respective ambient 

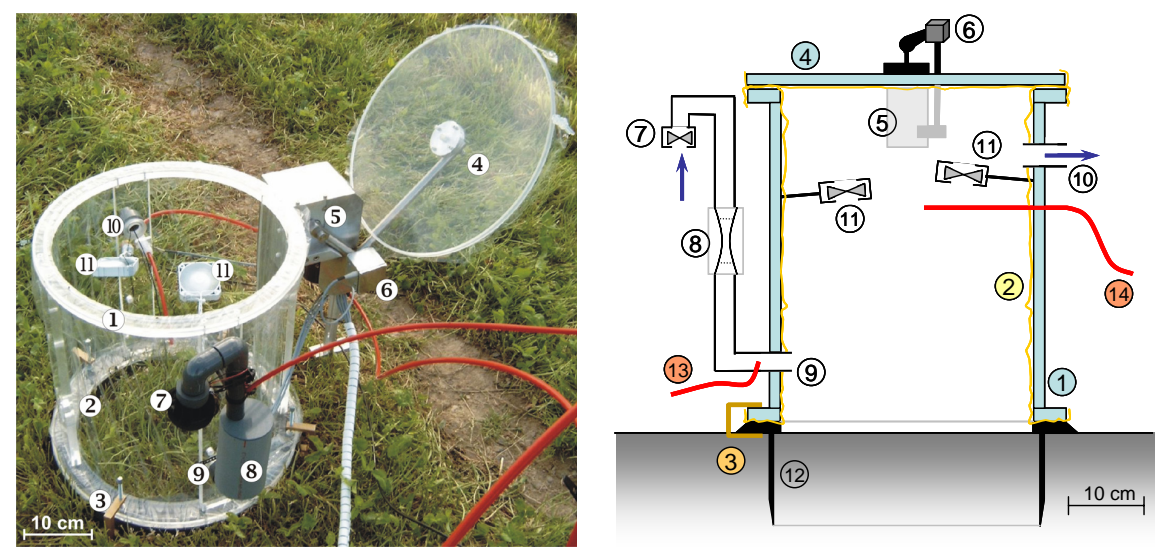

Fig. 2. Photograph and schematic of one individual dynamic chamber consisting of: (1) acrylic glass frame, (2) transparent FEP film (yellow parts in the scheme), (3) clamp to attach chamber to soil frame, (4) moving lid, (5) lid motor, (6) lid inclinometer, (7) purging fan with ambient air inlet, (8) mass flow meter, (9) chamber air inlet, (10) chamber air outlet, (11) mixing fan, (12) soil frame, (13) sample tube for ambient air, (14) sample tube for chamber air.

or chamber concentration (in contrast to the deposition processes). Thus the emission flux is not sensitive to the turbulence conditions in the air neither outside nor within the chamber, and a correction according to Eq. (5) is not necessary.

\subsubsection{Chemical reactions inside the chamber}

Reactive trace gases in the atmosphere, like e.g. $\mathrm{NO}, \mathrm{NO}_{2}$, and $\mathrm{O}_{3}$, may be subject to (photo-) chemical reactions with typical time scales of the same order of magnitude like the residence time of air in the chamber. In this case, the determination of surface exchange fluxes by the dynamic chamber method has to take into account the relevant chemical sources and sinks in the chamber volume. For the specific case of $\mathrm{NO}, \mathrm{NO}_{2}$, and $\mathrm{O}_{3}$ the main gas-phase reactions outside and inside the chamber are (Remde et al., 1993; Warneck, 2000):

$\mathrm{NO}+\mathrm{O}_{3} \rightarrow \mathrm{NO}_{2}+\mathrm{O}_{2}$

$\mathrm{NO}_{2}+h v \stackrel{\mathrm{O}_{2}}{\longrightarrow} \mathrm{NO}+\mathrm{O}_{3}(\lambda \leq 420 \mathrm{~nm})$

Formulating the reaction kinetics for $\mathrm{NO}$ in Reactions (R1) and (R2) yields:

$\frac{d \mu(\mathrm{NO})}{d t}=-k \times \mu(\mathrm{NO}) \times \mu\left(\mathrm{O}_{3}\right)$

$\frac{d \mu(\mathrm{NO})}{d t}=j\left(\mathrm{NO}_{2}\right) \times \mu\left(\mathrm{NO}_{2}\right)$

where $k$ is the first order reaction rate constant of Reaction (R1) (see Appendix A) and $j\left(\mathrm{NO}_{2}\right)$ is the photolysis rate of $\mathrm{NO}_{2}$. The resulting net gas-phase source
$\left(S_{\mathrm{gp}}\right)$ for NO within the chamber volume can be described as:

$$
\begin{array}{r}
S_{\mathrm{gp}}(\mathrm{NO})=V \times\left[j\left(\mathrm{NO}_{2}\right) \times \mu_{\text {cham }}\left(\mathrm{NO}_{2}\right)\right. \\
\left.-k \times \mu_{\text {cham }}(\mathrm{NO}) \times \mu_{\text {cham }}\left(\mathrm{O}_{3}\right)\right]
\end{array}
$$

For ozone and $\mathrm{NO}_{2}$, the reaction kinetics of the gas phase Reactions (R1) and (R2) are equal or opposite to that of NO, and thus the corresponding net chemical source is related to Eq. (8) as:

$S_{\mathrm{gp}}(\mathrm{NO}) \equiv S_{\mathrm{gp}}\left(\mathrm{O}_{3}\right) \equiv-S_{\mathrm{gp}}\left(\mathrm{NO}_{2}\right)$

Taking into account the net chemical source within the chamber volume, the mass budget in Eq. (1) has to be expanded for any of the three reactive trace gases to:

$$
\begin{aligned}
V \times \rho_{\mathrm{d}} \frac{d \mu_{\text {cham }}}{d t} & = \\
& A \times F_{\text {cham }}-Q \times \rho_{\mathrm{d}}\left[\mu_{\text {cham }}-\mu_{\text {amb }}\right]+S_{\mathrm{gp}}
\end{aligned}
$$

and the corresponding chamber flux Eq. (2) is modified to:

$$
F_{\text {cham }}=\frac{Q}{A} \rho_{\mathrm{d}} \times\left[\mu_{\text {cham }}-\mu_{\text {amb }}\right]-\frac{1}{A} S_{\mathrm{gp}}
$$

\subsection{Chamber design and operation}

Our design of the dynamic chamber system (see Fig. 2) aims at a minimised modification of the trace gas exchange (cf. Sect. 2.1.2) but is also based on practical requirements concerning robustness and maintenance in the field. The chamber body has a cylindrical shape with $0.35 \mathrm{~m}$ inner diameter and $0.43 \mathrm{~m}$ height, resulting in an enclosed surface area $(A)$ of $0.096 \mathrm{~m}^{2}$ and a headspace volume $(V)$ of $0.041 \mathrm{~m}^{3}$. The manufacturer details of the used materials and parts are listed in Table 1. The outer supporting frame and the 
Table 1. Manufacturer details for all parts of the dynamic chambers.

\begin{tabular}{|c|c|c|}
\hline Part & Manufacturer/Supplier & Specifications \\
\hline frame and lid & MPI workshop, Germany & acrylic glass, thickness $=12 \mathrm{~mm}$ \\
\hline FEP film & Saint Gobain, Germany & $\begin{array}{l}\text { FEP (fluorinated ethylene propylene) film, } \\
\text { thickness }=0.05 \mathrm{~mm} \text {, chemically inert, transparent for visible and UV } \\
\text { light }\end{array}$ \\
\hline Silicone straps & Dichtungstechnik Bensheim GmbH, Germany & transparent silicone cord, bulk stock, diameter $=5 \mathrm{~mm}$ \\
\hline DC motor with gear assembly & Bosch, Germany & model CDP, $24 \mathrm{~V}, 22 \mathrm{~W}$ \\
\hline lid inclinometer & Pewatron, Switzerland & $\begin{array}{l}\text { HALL effect inclinometer, } \\
\text { model UV-00H-SW2 }\end{array}$ \\
\hline soil collars & ART workshop, Switzerland & $\begin{array}{l}\text { PVC, thickness }=5 \mathrm{~mm} \text {, height }=12 \mathrm{~cm} \text {, } \\
\text { inner diameter }=35 \mathrm{~cm}\end{array}$ \\
\hline aluminium clamps & Bessey, Germany & aluminium mini clamp, type AM4 \\
\hline inlet fan & Micronel, Switzerland & Axial fan, model D344T012GK-2 \\
\hline mixing fan & Micronel, Switzerland & $\begin{array}{l}\text { Ultra Slim fan, model F62MM012GK-9, Teflon }{ }^{\circledR} \text { coating } \\
\text { by MPI workshop }\end{array}$ \\
\hline inlet/outlet adapter & MPI workshop, Germany & PVC tubing, inner diameter $=3 \mathrm{~cm}$ \\
\hline air mass flow sensor & Honeywell International Inc., USA & model AWM 700 \\
\hline particulate membrane filter & Pall Corporation, USA & $\begin{array}{l}\text { Zylon }{ }^{\mathrm{TM}} \text { membrane disc filters, model P4PH047, pore } \\
\text { size } 5 \mu \mathrm{m} \text {, diameter }=47 \mathrm{~mm}\end{array}$ \\
\hline in-line filter case & Entegris Inc., USA & Galtek® Integral Ferrule in-line filters \\
\hline tubing & div. & 1/4" PFA tubing \\
\hline solenoid valves & Entegris Inc., USA, & Galtek® Diaphragm Valves, 3-way, 1/4" orifice \\
\hline sample pump & KNF Neuberger GmbH & $\begin{array}{l}\text { LABOPORT®, model N } 810.3 \text { FT.18, all sample exposed } \\
\text { parts are PTFE coated }\end{array}$ \\
\hline heating tape & Electrolux, Sweden & model SLH 15/L300, self limiting \\
\hline
\end{tabular}

movable lid are made of acrylic glass. The inner walls consist of a thin transparent FEP film $(0.05 \mathrm{~mm})$ tube (welded from a $1.25 \times 0.53 \mathrm{~m}$ large FEP film sheet). The inner side of the lid is also covered by FEP film. The FEP film parts are fixed by elastic silicone straps running in $4 \mathrm{~mm}$ grooves at the outer sides of frame and lid. This provides an easy replacement of the FEP film parts when dirty or damaged. The chamber's lid is fixed to a lever arm which is moved by a DC motor with gear assembly mounted to the frame. An inclinometer mounted on the lever arm monitors the lid's angular position. In the field, the chamber is fixed on pre-installed PVC soil collars (depth $0.12 \mathrm{~m}$, thickness $5 \mathrm{~mm}$ ) by four aluminium clamps. Several holes in the supporting acrylic glass frame allow the installation of inlet and outlet ducts as well as of sample tubes, mixing fans, and sensors for environmental parameters.

The purging air flow through the chamber is established by a blowing axial inlet fan (range: $0-801 \mathrm{~min}^{-1}$ ) which is controlled by an air mass flow sensor (range: $0-2001 \mathrm{~min}^{-1}$ ). They are mounted outside the chamber frame and are connected via a $3 \mathrm{~cm}$ wide PVC inlet tube (Fig. 2). The purging air enters the chamber volume $0.11 \mathrm{~m}$ above ground, while the outlet hole $(3 \mathrm{~cm}$ diameter $)$ is located $0.31 \mathrm{~m}$ above ground on the opposite side. The mass flow sensors were calibrated before and after field application using a laboratory mass flow meter (M+W Instruments, Germany). The variation between individual calibrations was less than $0.5 \%$. Continuous turbulent mixing inside the chamber is maintained by two Teflon coated ultra slim fans $\left(3601 \mathrm{~min}^{-1}\right.$ at nominal voltage $12 \mathrm{~V} \mathrm{DC}$ ) blowing downwards.
The spectral radiation transmissivity of the chamber frame and body materials is illustrated in Fig. 3. In the wavelength range of the photosynthetic active radiation $(\lambda=400-700 \mathrm{~nm})$ the transmissivity of the FEP film is around 0.95 , while for the acrylic glass it is on average 0.81 . In the ultraviolet wavelength domain $(\lambda \leq 420 \mathrm{~nm}$, comprising the photolysis frequency range for $\mathrm{NO}_{2}\left(j\left(\mathrm{NO}_{2}\right)\right)$ ) the FEP film has an average transmissivity of 0.9 , while for the acrylic glass of frame and lid it is negligibly small. The average radiation transmissivity for the entire chamber volume is estimated as average of $50 \%$ FEP film only and 50\% FEP film plus acrylic glass. This results in effective transmissivity values of about 0.86 for PAR and 0.48 for $j\left(\mathrm{NO}_{2}\right)$. For results of field measurements of the chamber transmissivity for $j\left(\mathrm{NO}_{2}\right)$ we refer to Sect. 3.3.

Up to six chambers can be combined to one system (see Fig. 4a). Each chamber is connected to an individual controller module (ICO), which is installed in the field at 1-2 $\mathrm{m}$ distance from the chamber. A detailed schematic drawing of the ICO is displayed in Fig. 4b. The ICO supplies power for all consumers of the chamber (lid motor, purging and mixing fans). Further, it provides recording of the signals of operation-related sensors (flow meter, inclinometer) and various environmental sensors (probes for air temperature, soil temperature, soil water content, surface wetness). Three additional analogue input channels (0-10 V DC) and 3 analogue output channels (0-5 V DC) can be used to control additional measurement devices in the field. Finally, the ICO contains two PFA solenoid valves which control the gas sampling from the individual chambers to the gas analysers. 


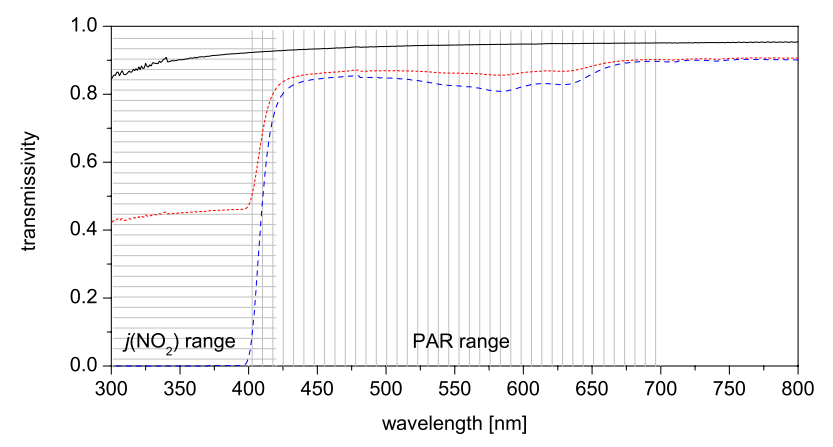

Fig. 3. Spectral radiation transmission of acrylic glass frame (blue dashed line), FEP film (black solid line), and complete chamber (calculated with FEP film $+50 \%$ acrylic glass, red dotted line). The shaded areas indicate the wavelength domains of $j\left(\mathrm{NO}_{2}\right)$ (horizontal lines) and PAR (vertical lines). Data provided by I. Trebs and J. Kesselmeier (personal communication, 2008).

The ICOs, which have unique addresses for serial bus communication, are connected in line by combined communication and power cables (24-30 V DC) and controlled by a central V25 microprocessor unit (see Fig. 4a). The V25 is programmed (PASCAL based code) to send control commands and to read out the data from the ICOs every second. Monitoring the signals of the inclinometer and mass flow meter, it controls the motor for lid opening and closing as well as the inlet fan for the purging air flow by $1 \mathrm{~s}$ feedback loops. Further, it controls the DC output for switching the solenoid valves inside the ICOs and the ICOs' DC output for the mixing fans. The V25 unit has eight analogue input channels (0-10 V DC) by which the signals of trace gas analysers and other instruments can be recorded every second, while eight analogue output channels (0-10 V DC) may be used to control additional external devices. The V25 microprocessor may be operated manually via built-in keypad and display. This allows the user to control the chambers independently from any measurement cycle, e.g. for testing the status of individual components. Automatic control can be performed via RS232 communication. In the present study, a LabView (National Instruments Corp.) program, running on a personal computer, was used. The LabView program reads and processes the data from the V25 (chamber status, environmental sensors, and gas analysers) and stores them on hard disk. Furthermore, it allows to set the parameters for the measurement cycle and activates (closing and purging) and deactivates (opening and stop purging) the chambers accordingly.

The sample air flow for trace gas analysis is independent from the purging air flow. Ambient air (with mixing ratio $\left.\mu_{\mathrm{amb}}\right)$ is sampled from the inlet duct $2 \mathrm{~cm}$ before entering the chamber volume (no. 13 in Fig. 2 ), while chamber air ( $\left.\mu_{\text {cham }}\right)$ is sampled from the centre of the chamber's headspace 25 $\mathrm{cm}$ above ground (no. 14 in Fig. 2). In order to minimise
Table 2. Specifications of gas analysers used with the dynamic chamber system.

\begin{tabular}{lcl}
\hline \multicolumn{1}{l}{ Species } & Analyzer & Precision \\
\hline \multicolumn{3}{c}{ Rümlang experiment } \\
\hline $\mathrm{NO}, \mathrm{NO}_{2}$ & Model 42C, Thermo Fisher Scientific, Waltham, USA & $0.2 \mathrm{ppb}, 0.3 \mathrm{ppb}$ \\
$\mathrm{O}_{3}$ & Model 49C, Thermo Fisher Scientific, Waltham, USA & $0.8 \mathrm{ppb}$ \\
$\mathrm{CO}_{2}, \mathrm{H}_{2} \mathrm{O}$ & LI-6262, Li-Cor, Lincoln, USA & $1.3 \mathrm{ppm}, 0.13 \%$ \\
\hline \multicolumn{3}{c}{ Oensingen experiment } \\
\hline $\mathrm{CO}_{2}, \mathrm{H}_{2} \mathrm{O}$ & LI-6262, Li-Cor, Lincoln, USA & $1.3 \mathrm{ppm}, 0.13 \%$ \\
methanol & PTR-MS, Ionicon Analytik GmbH, Innsbruck, Austria & $0.1 \mathrm{ppb}$ \\
\hline
\end{tabular}

deposition losses in the sampling system all parts in contact with the sample gas are made of Teflon (PFA or PTFE). To prevent contamination of tubing and analysers, particulate matter is removed from the sample air by PTFE particulate filters (pore size: $5 \mu \mathrm{m}$ ). The sequential sampling of inlet and chamber air and the switching between multiple chambers is controlled by two 3-way PFA solenoid valves housed within the ICO control module of each chamber (Fig. 4b). As illustrated in Fig. 4a, this enables the sampling air entering one central sampling tube that connects up to six chambers sequentially. In order to prevent condensation in the central sampling tube it is heated by a self-limiting heating tape to a few degrees above ambient temperature. The sampling air flow is established by a central PTFE membrane pump (see Fig. 4a). A large sampling air flow of $10-151 \mathrm{~min}^{-1}$ ensures short residence time in the tubes and allows the simultaneous detection of various trace gases by different analysers. The entire chambers and all controlling devices are built by the mechanic and the electronics workshops of the Max Planck Institute for Chemistry (Mainz, Germany).

\subsection{Field experiments}

The dynamic chamber system was tested and applied during two field experiments at managed grassland sites on the Swiss Central Plateau. As part of the COST 852 experiment (Quality legume-based forage systems for contrasting environments, see Nyfeler et al., 2009) in Rümlang, $\left(47^{\circ} 26^{\prime} \mathrm{N}, 8^{\circ} 32^{\prime} \mathrm{E}, 486 \mathrm{~m}\right.$ a.s.l. $)$, the surface exchange of $\mathrm{CO}_{2}, \mathrm{H}_{2} \mathrm{O}, \mathrm{NO}, \mathrm{NO}_{2}$, and $\mathrm{O}_{3}$ of four differently managed grass and clover plots $\left(18 \mathrm{~m}^{2}\right.$ each) was measured during the 2004 and 2005 vegetation periods. Plots \#1 and \#2 had been planted with White clover and received a high $\left(450 \mathrm{~kg} \mathrm{Nha}^{-1} \mathrm{y}^{-1}\right)$ and low $\left(50 \mathrm{~kg} \mathrm{Nha}^{-1} \mathrm{y}^{-1}\right)$ fertilisation, respectively. Plots \#3 and \#4 had been planted with English ryegrass receiving similar high and low fertilisation levels.

Usually, one chamber was applied on each of the four plots. In addition, one "blank chamber" was operated on the site. In the blank chamber, the surface exchange is excluded by closing the bottom of the chamber by inert FEP film. The blank chamber is used to check for unconsidered 
(a)

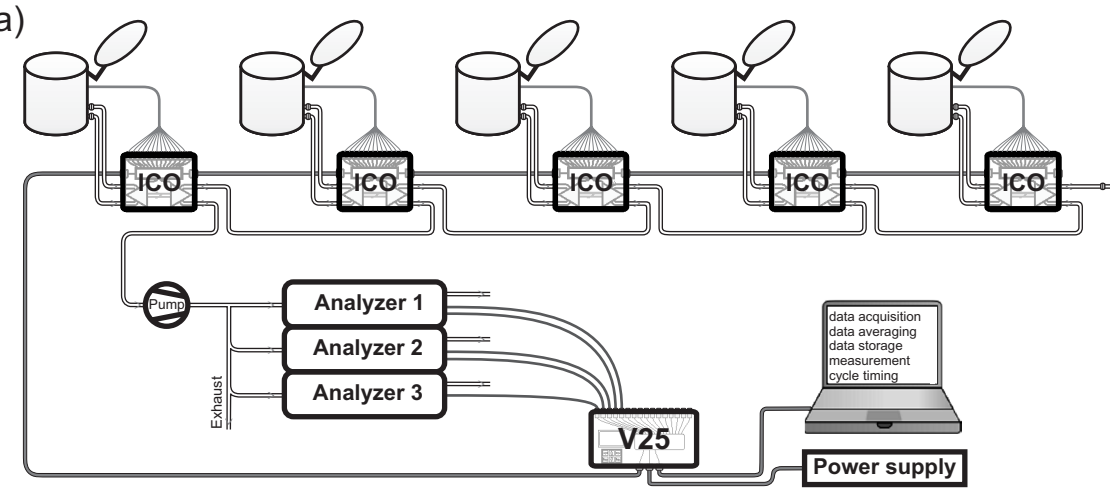

(b)

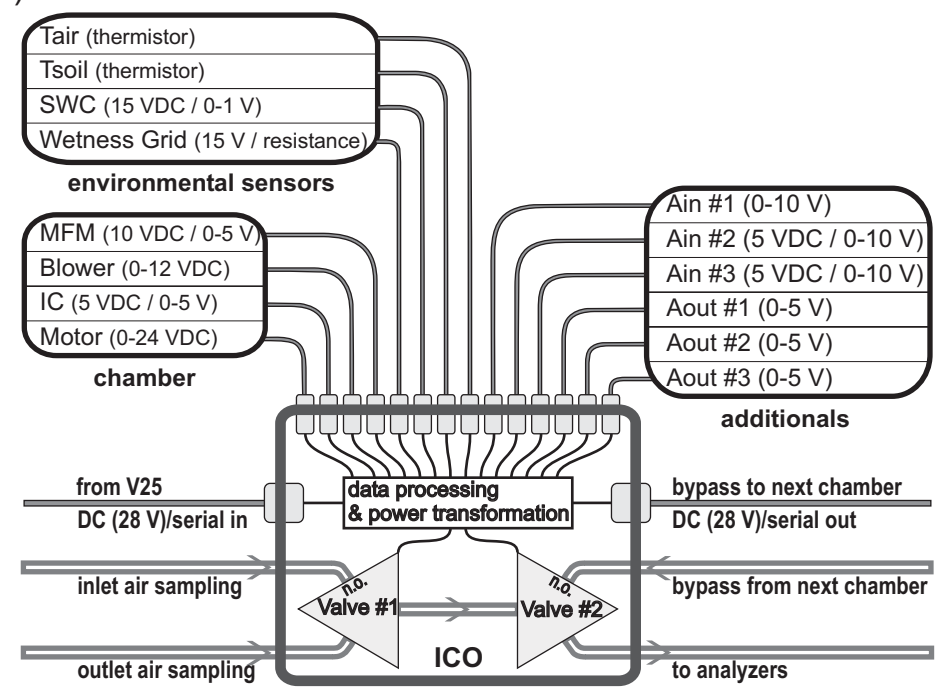

Fig. 4. (a) Schematic setup of a sampling system with five combined dynamic chambers, as applied in the Rümlang field experiment. Black lines are cables for data acquisition and control; open lines are PFA sampling tubes. (b) Schematic drawing of the individual controller module (ICO). Filled lines are cables for RS232 communication, control, and data acquisition, open lines are PFA gas sampling tubes (the gas flow direction is indicated by arrows).

chemical production or destruction processes within the chamber (in the gas phase or at the wall surfaces). The five chambers were sampled serially within each hour (cf. Fig. 5a). Each individual chamber was closed for only $13 \mathrm{~min}$ to ensure minimum modification of environmental conditions. One minute before an individual measuring period (of $12 \mathrm{~min}$ duration) the normally open chamber lid was closed and the purging air flow was established. At the beginning of the measuring period, Valve \#2 (see Fig. 4b) was switched to sample ambient air from the chamber inlet for $4 \mathrm{~min}$. Afterwards, chamber air was sampled for $4 \mathrm{~min}$ by switching Valve \#1, followed by a second sampling of ambient air. At the end of the measuring period Valve \#2 was disabled, the purging air flow was stopped, and the lid was opened. Measurements of trace gas concentrations were performed by chemiluminescence (NO,
$\left.\mathrm{NO}_{2}\right)$, UV-absorption $\left(\mathrm{O}_{3}\right)$, and non-dispersive infra-red absorption $\left(\mathrm{CO}_{2}, \mathrm{H}_{2} \mathrm{O}\right)$ analysers with a temporal resolution of $20 \mathrm{~s}$. The analyser specifications are listed in Table 2 . It has to be noted that the aplied $\mathrm{NO} / \mathrm{NO}_{2}$ analyser uses a molybdenum converter for $\mathrm{NO}_{2}$ that is not fully specific but can also convert other oxigenated nitrogen compounds to NO. However, an intercomparison with a more specific photolytic converter showed that this interference is usually less than $10 \%$ at the field site.

The second field experiment was conducted near the village of Oensingen in the north-western part of Switzerland $\left(7^{\circ} 44^{\prime} \mathrm{E}, 47^{\circ} 17^{\prime} \mathrm{N}, 450 \mathrm{~m}\right.$ a.s.l.) (see Ammann et al., 2007). As part of the EU project CarboEurope-IP and the national project COGAS, surface exchange fluxes of $\mathrm{CO}_{2}$ and volatile organic compounds (VOC) were measured on an intensively managed grassland $(0.77 \mathrm{ha})$. At Oensingen 
(a)

(b)

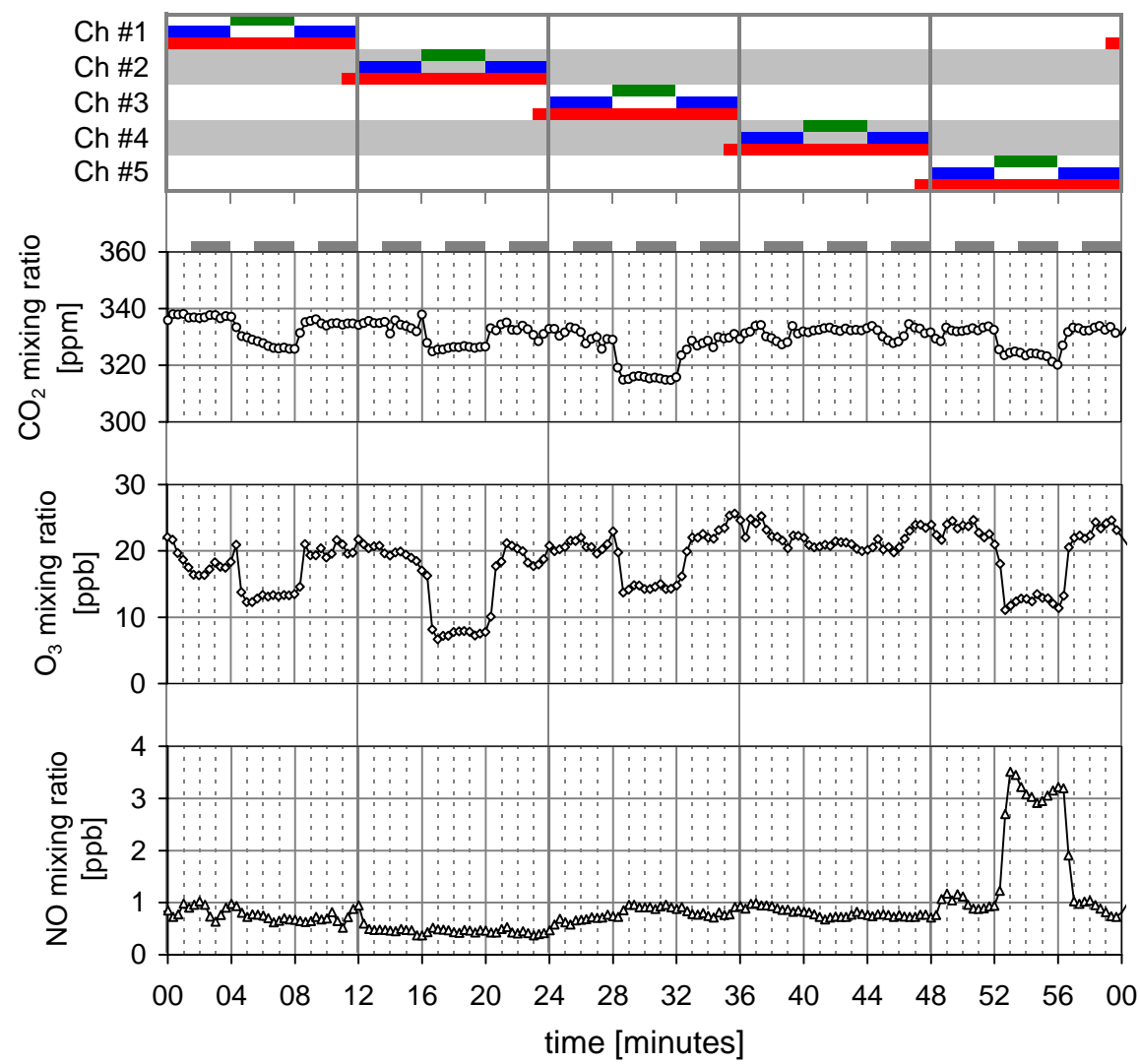

Fig. 5. Chamber control scheme for 5 individual chambers ( $\mathrm{Ch} \# 1$ to $\mathrm{Ch} \# 5)$ and typical time series of trace gas mixing ratios over one full measurement cycle of $1 \mathrm{~h}$ during the Rümlang field experiment. (a) Control scheme indicating periods of closed lid (red bars), sampling/analysis of ambient air (blue bars), and sampling/analysis of chamber air (green bars). (b-d) Original time series ( $20 \mathrm{~s}$ resolution) of $\mathrm{CO}_{2}, \mathrm{O}_{3}$, and $\mathrm{NO}$ mixing ratios. For flux calculations the first $100 \mathrm{~s}$ after each valve switching have been discarded (see Sect. 3.1.1). The effective averaging intervals are indicated by grey bars on top of panel (b).

the dynamic chamber system comprised three chambers (two regular chambers and one blank chamber) with individual measurement intervals of 10 min resulting in a total measurement cycle period of $30 \mathrm{~min}$. Alternating with the chamber measurements, field scale methanol fluxes were measured using the eddy covariance method for $30 \mathrm{~min}$ within each hour (Brunner et al., 2007a). Field scale $\mathrm{CO}_{2}$ fluxes were measured continuously with a second eddy covariance system (Ammann et al., 2007). These data were used to validate the quality of the fluxes measured with the dynamic chambers. The instruments used in this experiment and their specifications are also listed in Table 2.

Chamber fluxes of $\mathrm{CO}_{2}, \mathrm{H}_{2} \mathrm{O}$, and methanol were calculated according to Eq. (2), those for $\mathrm{NO}, \mathrm{NO}_{2}$ and $\mathrm{O}_{3}$ according to Eqs. (8), (9), and (11). Due to the alternating (non-simultaneous) measurement of the ambient and chamber concentration, a temporally symmetric measurement schedule $\left(\mu_{\mathrm{amb}} \rightarrow \mu_{\mathrm{cham}} \rightarrow \mu_{\mathrm{amb}}\right)$ was used for each chamber as illustrated in Fig. 5a, and the ambient concentration was averaged over both measurement phases of $\mu_{\mathrm{amb}}$. In this way, temporal (linear) trends of the ambient concentration could be accounted for. However, short term variations of the ambient concentration could lead to an enhanced scatter of the chamber flux results. To limit this effect, the standard deviation of individual (20 s) measurements of $\mu_{\mathrm{amb}}$ was used as rejection criterion. Based on statistical analysis, individual thresholds for the standard deviations of $\mathrm{NO}, \mathrm{NO}_{2}$, and $\mathrm{O}_{3}$, were determined to $1 \mathrm{ppb}, 1.7 \mathrm{ppb}$, and $7 \mathrm{ppb}$, respectively. All cases exceeding the threshold for at least one of the mentioned gases were rejected.

\section{Results}

\subsection{Equilibration after chamber closure}

For being able to perform flux measurements of up to six chambers with a high temporal resolution of about $1 \mathrm{~h}$, our chamber system has been designed to operate with short measurement (closing) periods. Therefore fast equilibration 


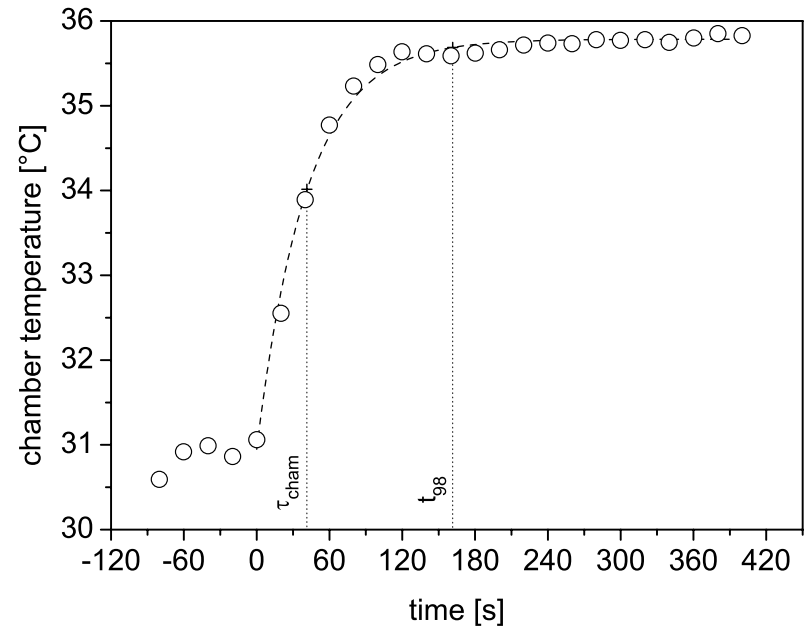

Fig. 6. Exemplary field observation of chamber temperature equilibration after closing of the chamber lid at time $=0 \mathrm{~s}$ ( 23 August 2004 15:00 LT, $G=540 \mathrm{~W} \mathrm{~m}^{-2}$ ). The dashed line represents a fitted exponential function according to Eq. (12). The dotted anchor lines indicate the fitted $\tau_{\text {cham }}$ and $t_{98}$, respectively (see text).

of the chamber air after closing the lid is crucial. The time necessary for reaching the new dynamic equilibrium was investigated by analysis of measured time series (Sect. 3.1.1) as well as by numerical simulation studies (Sect. 3.1.2).

\subsubsection{Definitions and exemplary observations}

The equilibration of the chamber mixing ratio $\left(\mu_{\text {cham }}\right)$ for an inert trace gas is described by the differential Eq. (1). Its analytical solution is a first order exponential decay function:

$\mu_{\text {cham }}(t)=\mu_{\text {amb }}+\frac{A \times F_{\text {cham }}}{Q \times \rho_{\mathrm{d}}}\left(1-\mathrm{e}^{-t / \tau_{\text {cham }}}\right)$

The constant mixing ratio $\mu_{\mathrm{amb}}$ of the inflowing ambient air also represents the initial chamber concentration at $t=0$ (just before closing). The time scale $\tau_{\text {cham }}=V / Q$ is the 1/e-response time of the exponential function and represents the mean residence time of air within the well-mixed chamber volume. For the standard purging rate $Q=601 \mathrm{~min}^{-1}$ used in this study, $\tau_{\text {cham }}$ results in $41.4 \mathrm{~s}$. For a reasonable approximation of the "full" equilibration, we will use the time interval for $98 \%$ approximation $\left(t_{98}\right)$, which equals $162 \mathrm{~s}$ in the present case, and corresponds to about $4 \times \tau_{\text {cham }}$.

A direct observation of the equilibration process for the trace gas concentrations in the chamber is hardly possible with our measurement setup, due to the delay effects introduced by the sampling tube, the pump (see Fig. 4a), and due to limited response times of the analysers. However, the temporal development of the equilibration is also reflected in the chamber air temperature, which is recorded without any time delay. A typical example for the measured chamber air temperature before and after lid closure is shown in Fig. 6. An exponential fit to the data yielded values of $\tau_{\text {cham }}=40.9 \mathrm{~s}$ and $t_{98}=160 \mathrm{~s}$, nearly identical to the values derived from residence time considerations above. The displayed example was chosen for its large temperature change but similar response times could be observed for almost all field measurements.

Time series of trace gas concentration measurements in the field are shown in Fig. 5b-d. The equilibration process after lid closure is generally not visible in the data, because the respective time periods are used to sample ambient air (partly of the previous chamber, see Fig. 5a). The observed concentration changes are due to switching between ambient and chamber air sampling. They show response times $\left(t_{98}\right)$ of $30 \mathrm{~s}$ to $60 \mathrm{~s}$ that do not represent the chamber equilibration but mainly result from the delay effects mentioned above. For that reason, data obtained within in the first $100 \mathrm{~s}$ after valve switching were generally discarded from data evaluation (effective averaging intervals are indicated as grey bars in Fig. 5b).

\subsubsection{Simulations}

Chamber equilibration characteristics for reactive trace gases may not only depend on chamber geometry and purging flow. The influence of net chemical sources (see Sect. 2.1.3) and of the individual surface exchange flux has also to be considered. In order to investigate and illustrate these influences simulation studies for $\mathrm{NO}, \mathrm{NO}_{2}$, and $\mathrm{O}_{3}$ were conducted. The temporal development of the trace gas mixing ratios is described by Eq. (10) with the net chemical source $S_{\mathrm{gp}}$ as defined in Eqs. (8) and (9). Since $S_{\mathrm{gp}}$ itself is a function of the mixing ratios of the three reactive trace gases, Eq. (10) can not be solved analytically but was used for numerical integration with a time step of $1 \mathrm{~s}$.

Selected simulation results are summarised in Fig. 7. They show the temporal development of the NO mixing ratio after chamber closure (at $t=0 \mathrm{~s}$ ) depending on individual controlling parameters. For each equilibration curve $t_{98}$ is indicated. The simulations in Fig. 6a and b were calculated without any gas-phase chemistry and thus represent the basic case of an inert trace gas. As expected according to Eq. (12), $t_{98}$ increases proportionally with $Q$ in Fig. 7a, which corresponds well with experimental findings of Suh et al. (2006) and simulation studies of Gao and Yates (1998). In contrast, $t_{98}$ is independent from the NO emission flux (Fig. 7b). As mentioned above, a high purging rate $\left(Q=601 \mathrm{~min}^{-1}\right)$ was chosen as operational standard for the field experiments in order to achieve the desired short measurement intervals. This purging rate was also used for the simulations shown in Fig. 7b-d. For the inert case (Fig. 7b), it results in a $t_{98}$ value of $162 \mathrm{~s}$, equal to the analytical solution in the preceding section. When chemical reactions are included $\left(\mu_{\text {cham }}\left(\mathrm{O}_{3}\right) \neq 0\right)$, the 

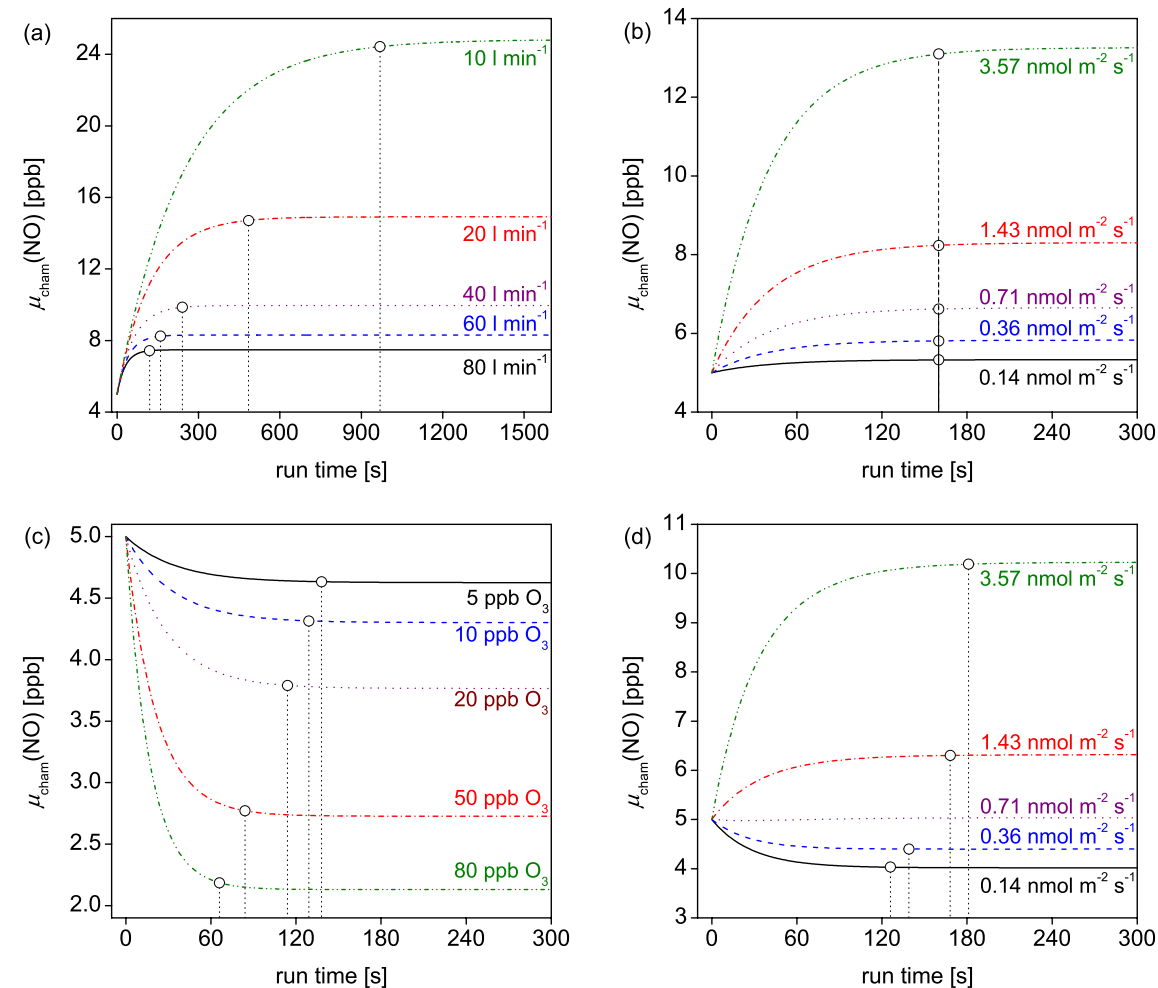

Fig. 7. Numerical simulations of the temporal development of the chamber NO mixing ratio $\mu_{\text {cham }}$ (NO) after closing the lid. Calculations are based on Eq. (10). Circles with dotted anchor lines represent the $98 \%$ equilibration time ( $\left.t_{98}\right)$. All simulations were performed with a constant ambient NO mixing ratio of $5 \mathrm{ppb}$, also representing the initial value for $\mu_{\text {cham }}(\mathrm{NO})$. For each individual graph, one parameter was varied (indicated by the coloured curve labels), while the other parameters were held constant: (a) varying purging flow $(Q)$; constant $\mu_{\mathrm{amb}}\left(\mathrm{O}_{3}\right)=0 \mathrm{ppb}$ and $F(\mathrm{NO})=1.43 \mathrm{nmol} \mathrm{m}^{-2} \mathrm{~s}^{-1}$. (b) varying soil $\mathrm{NO}$ emission flux $(F(\mathrm{NO}))$; constant $\mu_{\mathrm{amb}}\left(\mathrm{O}_{3}\right)=0 \mathrm{ppb}$ and $Q=601 \mathrm{~min}^{-1}$. (c) varying ambient ozone mixing ratio $\left(\mu_{\mathrm{amb}}\left(\mathrm{O}_{3}\right)\right)$; constant $F(\mathrm{NO})=0 \mathrm{nmol} \mathrm{m}^{-2} \mathrm{~s}^{-1}$ and $Q=601 \mathrm{~min}^{-1}$. (d) varying soil NO emission flux $(F(\mathrm{NO}))$; constant $\mu_{\mathrm{amb}}\left(\mathrm{O}_{3}\right)=20 \mathrm{ppb}$ and $Q=601 \mathrm{~min}^{-1}$.

equilibration time is not constant anymore, but varies with the concentration of the reactant $\mathrm{O}_{3}$ (Fig. 7c) and/or also with the NO emission flux (Fig. 7d). However, even for extreme cases within the chosen parameter range, $t_{98}$ is only moderately increased and does not exceed $200 \mathrm{~s}$. The curve for $F_{\text {cham }}(\mathrm{NO})=0.71 \mathrm{nmol} \mathrm{m}^{-2} \mathrm{~s}^{-1}$ in Fig. $7 \mathrm{~d}$ represents a special case, in which the NO soil emission is just counterbalanced by the chemical reaction of $\mathrm{NO}$ with $\mathrm{O}_{3}$ leading to an almost constant $\mathrm{NO}$ mixing ratio with time. It should be noted, that for $\mathrm{NO}$ emissions less than $0.71 \mathrm{nmol} \mathrm{m}^{-2} \mathrm{~s}^{-1}, \mu_{\text {cham }}(\mathrm{NO})$ becomes smaller than $\mu_{\mathrm{amb}}(\mathrm{NO})$ and hence the concentration difference changes sign in Eq. (11). Consequently, the flux evaluation without considering net gas-phase sources (i.e. applying Eq. 2 instead of Eq. 11) would lead to the wrong result of negative chamber fluxes (i.e. NO deposition).

The concentrations of $\mathrm{O}_{3}$ and $\mathrm{NO}_{2}$ (not shown) generally revealed a time response very similar to that of NO. Based on the simulation results the time between lid closure and the start of sampling of the chamber air was set to at least 4 min (see Fig. 5a), which is well above the maximum of simulated equilibration times.

\subsection{Modification of the turbulent transport by the chamber}

\subsubsection{Purging resistance $R_{\text {purge }}$ and mixing resistance $R_{\text {mix }}$}

In order to estimate and, if necessary, to correct for the effect of the chamber on the aerodynamic transport of trace gases (see Fig. $1 \mathrm{~b}$ and Eq. 5), the resistances $R_{\text {purge }}, R_{\text {mix }}$, and $R_{\mathrm{b}}^{*}$ had to be quantified for representative conditions. According to the rules of the resistance analogy, $R_{\text {purge }}$ is implicitely defined by:

$F_{\text {cham }}=\frac{1}{R_{\text {purge }}} \rho_{\mathrm{d}}\left(\mu_{\text {cham }}-\mu_{\text {amb }}\right)$

Comparison of Eq. (13) with Eq. (2) yields $R_{\text {purge }}=A / Q=100 \mathrm{~s} \mathrm{~m}^{-1}$. The air within the chamber volume is mixed by the purging air flow and additionally by two large mixing fans (see Fig. 2). $R_{\text {mix }}$ was studied by measuring the air movement within the (empty) chamber volume using a hot-wire anemometer. Figure 8 shows the corresponding results for a grid of vertical and horizontal positions. The air velocity is generally between $0.3 \mathrm{~m} \mathrm{~s}^{-1}$ and $2 \mathrm{~m} \mathrm{~s}^{-1}$ with an average value of about $0.75 \mathrm{~m} \mathrm{~s}^{-1}$. 


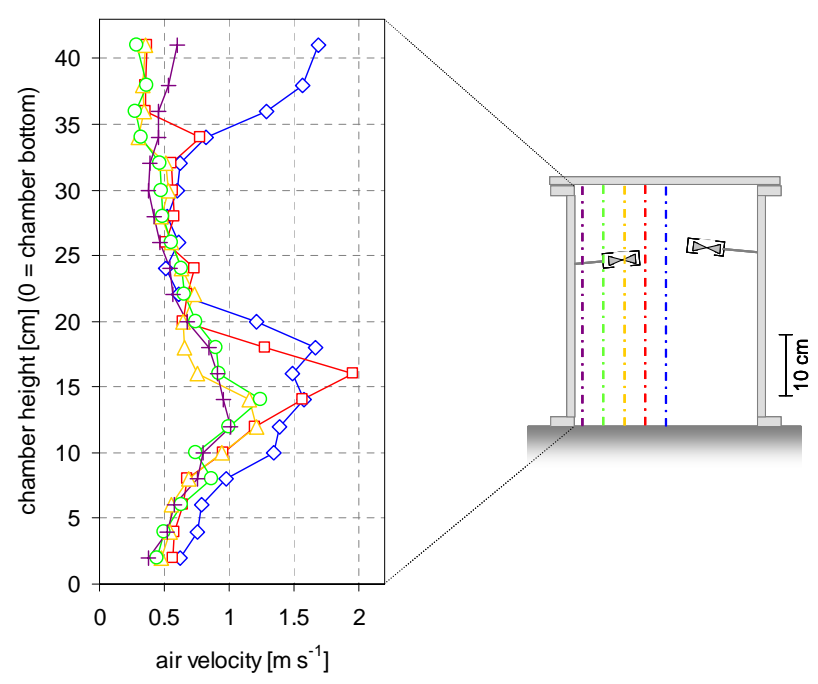

Fig. 8. Vertical profiles of air velocity inside the dynamic chamber measured by a hot-wire anemometer. The air movement resulted from the two displayed mixing fans as well as from the purging air flow $\left(Q=601 \mathrm{~min}^{-1}\right)$. The coloured vertical lines in the chamber sketch indicate the different horizontal positions of the displayed velocity profile measurements (with corresponding colours) within the cylindrical chamber.

Supposing an internal re-circulation of the chamber air with this velocity, its inverse value may be used as an estimate for $R_{\text {mix }}\left(\approx 1.5 \mathrm{~s} \mathrm{~m}^{-1}\right)$. This low value indicates a very efficient mixing of the chamber air, which was also demonstrated in laboratory experiments (not shown), where smoke was added to the inlet of a chamber. It was observed that the entire chamber volume became filled with smoke within less than $2 \mathrm{~s}$. These results show that $R_{\text {mix }}$ is very small in comparison to $R_{\text {purge }}\left(100 \mathrm{~s} \mathrm{~m}^{-1}\right)$ and to the other relevant resistances (see next Section). It is therefore generally neglected in the following evaluation.

The effective mixing of chamber air, even inside a dense vegetation canopy, is demonstrated by measurements of the $\mathrm{O}_{3}$ mixing ratio within a closed chamber on a mature clover plot (canopy height $\approx 0.2 \mathrm{~m}$, LAI=5). It was measured at two heights, one above (at $26.5 \mathrm{~cm}$ ) and the other deep in the clover canopy (at $2.5 \mathrm{~cm}$ ). The results, in form of a regression analysis, are shown in Fig. 9. The $\mathrm{O}_{3}$ mixing ratio in the canopy was on average only $8 \%$ lower than in the headspace above the canopy, indicating reasonably well mixed conditions even with dense vegetation present.

\subsubsection{Quasi-laminar boundary layer resistance $R_{\mathrm{b}}^{*}$}

Due to the high purging air flow and the additional strong mixing of the chamber volume by two fans, the bulk boundary layer resistance inside the chamber $\left(R_{\mathrm{b}}^{*}\right)$ is supposed to be smaller than outside (or possibly in the same order of magnitude, if ambient conditions are characterised

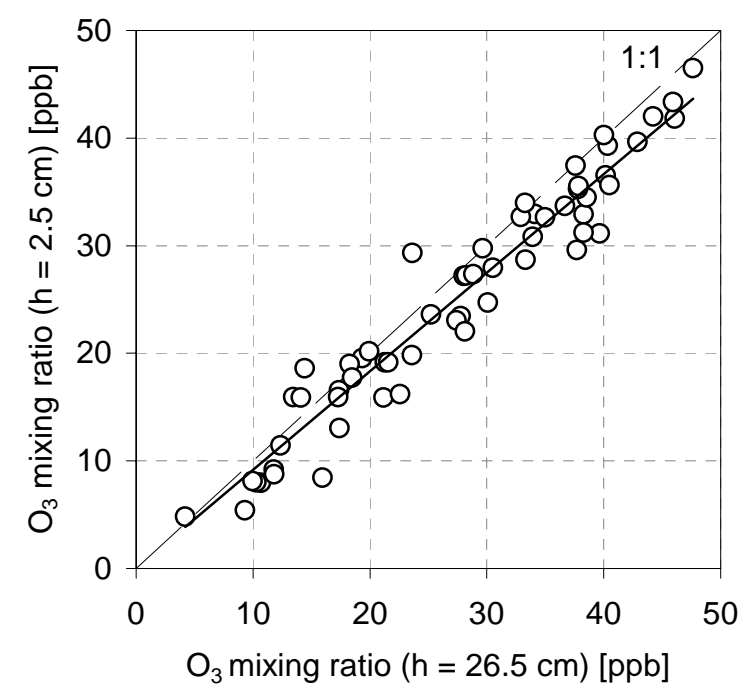

Fig. 9. Inside the closed dynamic chamber: $\mathrm{O}_{3}$ mixing ratio at $2.5 \mathrm{~cm}$ (inside canopy) vs. $\mathrm{O}_{3}$ mixing ratio at $26.5 \mathrm{~cm}$ (above canopy). Measurements have been performed at the Rümlang field site over White clover $(h \approx 20 \mathrm{~cm}, \mathrm{LAI}=5)$ during 8-10 September 2004, when global radiation ranged between 0 and $750 \mathrm{~W} \mathrm{~m}^{-2}$. The dashed line indicates the $1: 1$ line, the straight line represents the linear fit on the data points (slope $=0.92$, $\left.R^{2}=0.94, n=59\right)$. Chambers were operated in the standard mode $\left(Q=601 \mathrm{~min}^{-1}\right)$.

by high wind speeds and/or strong convection). The effective value of $R_{\mathrm{b}}^{*}$ during applications with grass vegetation is difficult to quantify. However, it can be approximated or at least constrained by indirect approaches. Using a saturated potassium iodide (KI) solution (representing an ideal sink for ozone, i.e. $\left.R_{\mathrm{c}} \approx 0\right), R_{\mathrm{b}}^{*}$ was determined from ozone deposition experiments in the laboratory (see Galbally and Roy, 1980; Ludwig, 1994; Gut et al., 2002b). A petri dish ( $23 \mathrm{~cm}$ dia.) filled with saturated KI solution was placed at the bottom of an otherwise empty chamber. The measurements under standard operation conditions showed a total deposition resistance $R_{\text {purge }}+R_{\text {mix }}+R_{\mathrm{b}}^{*}+R_{\mathrm{c}}=185 \mathrm{~s} \mathrm{~m}^{-1}$ (related to the chamber surface area). Since both, $R_{\mathrm{c}}$ and $R_{\text {mix }}$, are supposed to be negligible and $R_{\text {purge }}$ equals $100 \mathrm{~s} \mathrm{~m}^{-1}$ (see above), the boundary layer resistance for a flat liquid surface in an empty chamber is estimated to $R_{\mathrm{b}}^{*}$ (liq. surface $)=85 \mathrm{~s} \mathrm{~m}^{-1}$. The obtained value is higher than the one reported by Gut et al. (2002b) for a smaller chamber and lower than the result of Galbally and Roy (1980) for a much larger chamber. Galbally and Roy (1980) only reported results for $\left(R_{\mathrm{mix}}+R_{\mathrm{b}}^{*}\right)$, but due the strong mixing in their chamber, $R_{\text {mix }}$ is supposed to be negligible, too.

According to our chosen laboratory setup, the obtained value for $R_{\mathrm{b}}^{*}$ is only representative for deposition to a flat surface, e.g. smooth bare soil. With the presence of vegetation in the chamber, the effective surface area for 
trace gas deposition is much larger, and consequently $R_{\mathrm{b}}^{*}$ is assumed to be reduced according to the leaf area (see Galbally and Roy, 1980). The effect of vegetation in the chamber on $R_{\mathrm{b}}^{*}$ can be constrained by specific field observations. For a trace gas with zero compensation point like ozone, the combination of Eqs. (4) and (13) and neglecting $R_{\text {mix }}$ yields:

$R_{\mathrm{b}}^{*}=\frac{R_{\text {purge }}}{\left(\frac{\mu_{\text {amb }}\left(\mathrm{O}_{3}\right)}{\mu_{\text {cham }}\left(\mathrm{O}_{3}\right)}-1\right)}-R_{\mathrm{c}}\left(\mathrm{O}_{3}\right)$

In order to use Eq. (14), the value of $R_{\mathrm{c}}\left(\mathrm{O}_{3}\right)$ has to be known a priori, which is generally not the case for field measurements. Yet, a constraint for $R_{\mathrm{c}}\left(\mathrm{O}_{3}\right)$ is provided by Wesely (1989) and Nussbaum and Fuhrer (2000), who reported minimum values for fully developed grass canopies of about $100 \mathrm{~s} \mathrm{~m}^{-1}$. Minimum $R_{\mathrm{c}}\left(\mathrm{O}_{3}\right)$ values are expected to occur under optimum conditions for stomatal ozone uptake, i.e. high radiation and a high leaf area index (LAI). Such favourable conditions prevailed during 4 to 7 June 2004 in the Rümlang experiment. Corresponding ambient and chamber ozone mixing ratios obtained over fully developed ryegrass (LAI=5) are plotted in Fig. 10. The inverse of the regression line slope provides the desired ratio $\mu_{\mathrm{amb}}\left(\mathrm{O}_{3}\right) / \mu_{\text {cham }}\left(\mathrm{O}_{3}\right)=1.82 \pm 0.06$. Hence, according to Eq. (14), $R_{\mathrm{b}}^{*}$ is estimated to $22 \pm 9 \mathrm{~s} \mathrm{~m}^{-1}$ (with $R_{\text {purge }}=100 \mathrm{~s} \mathrm{~m}^{-1}$, Sect. 3.2.1). This value is about four times smaller than the result for a smooth ground surface as derived above. A very similar reduction of $R_{\mathrm{b}}^{*}$ was also observed by Galbally and Roy (1980) between smooth surfaces and grassed sites. In order to combine and reconcile the two constraining results for $R_{\mathrm{b}}^{*}$ we propose the following parameterisation as a function of the leaf area index:

$R_{\mathrm{b}}^{*}(\mathrm{LAI})=R_{\mathrm{b}}^{*}($ liq. surface $) \times \frac{1}{1+\mathrm{LAI}}$

For the field measurements with $\mathrm{LAI}=5$, this function yields a resistance of $17 \mathrm{~s} \mathrm{~m}^{-1}$ which is close to the observed value resulting from Eq. (14).

\subsubsection{Temperature and humidity conditions in the chamber}

Similar to the ozone mixing ratio, temperature and humidity conditions in the chamber headspace are also determined by the relative magnitude of the chamber resistances (Fig. 1b). Since $R_{\mathrm{b}}^{*}$ was found to be generally smaller than $R_{\text {purge }}$ (and $R_{\mathrm{c}}$ for temperature transfer is zero), the temperature inside the chamber is expected to be closer to the leaf temperature than to the ambient temperature. In Fig. 11a measurements of air temperature in the headspace of the chamber are compared for closed and open chamber conditions. The data obtained in the open chamber are considered to represent ambient conditions. The temperature within the closed chamber deviates from the ambient temperature by -1 to +6 degrees, with an increasing trend towards higher

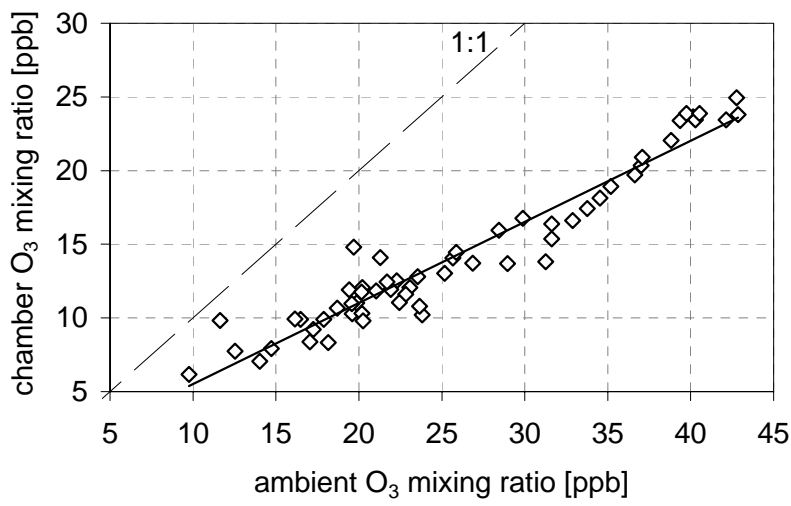

Fig. 10. Chamber vs. ambient $\mathrm{O}_{3}$ mixing ratios of a dynamic chamber operated on ryegrass $(\mathrm{LAI}=5)$ during daytime $\left(G \geq 200 \mathrm{~W} \mathrm{~m}^{-2}\right), 04-07$ June 2004, at the Rümlang field site. The dashed line indicates the 1:1 line, the straight line represents the linear fit (with zero offset) to the data points (slope $=0.55 \pm 0.02$, $R^{2}=0.93, n=58$ ). The chamber was operated in the standard mode $\left(Q=601 \mathrm{~min}^{-1}\right)$.

temperatures. As shown in Fig. 11b this can be explained by the effect of global (shortwave solar) radiation that heats the leaf surfaces. Similar to trace gases, the observed difference between chamber and ambient air qualitatively indicates the sensible heat flux from the vegetation to the atmosphere, although it may be confounded by interaction between the radiation and materials of the chamber. It is known from micrometeorological studies (see Oke, 1987), that - particularly for fully developed and dense vegetation canopies - a large part of the available radiation energy is transferred into latent heat, i.e. transpiration and evaporation of water leads to a flux of water vapour into the atmosphere. Consequently, the water vapour flux from the grass vegetation enclosed by the chamber implies a difference between the chamber and ambient $\mathrm{H}_{2} \mathrm{O}$ mixing ratios (Eq. 2). According to the resistance concept (Fig. 1b), the $\mathrm{H}_{2} \mathrm{O}$ mixing ratio within the chamber lies between the saturated conditions in the leaf stomata (depending on leaf temperature) and the respective ambient mixing ratio. The relation between chamber and ambient $\mathrm{H}_{2} \mathrm{O}$ mixing ratios measured at the Rümlang field site during August/September 2004 are shown in Fig. 11c. The resulting difference, which is proportional to the water vapour (latent heat) flux, is linearly related to the global radiation (see Fig. 11d) like the air temperature difference.

\subsection{Modification of $\mathrm{NO}_{2}$ photolysis in the chamber}

The correct calculation of surface exchange fluxes for $\mathrm{NO}, \mathrm{NO}_{2}$ and $\mathrm{O}_{3}$ has to consider the contribution of fast chemical gas phase reactions according to Eqs. (8) to (11). For this purpose, the photolysis rate $j\left(\mathrm{NO}_{2}\right)$ within the chamber volume needs to be known. It is 

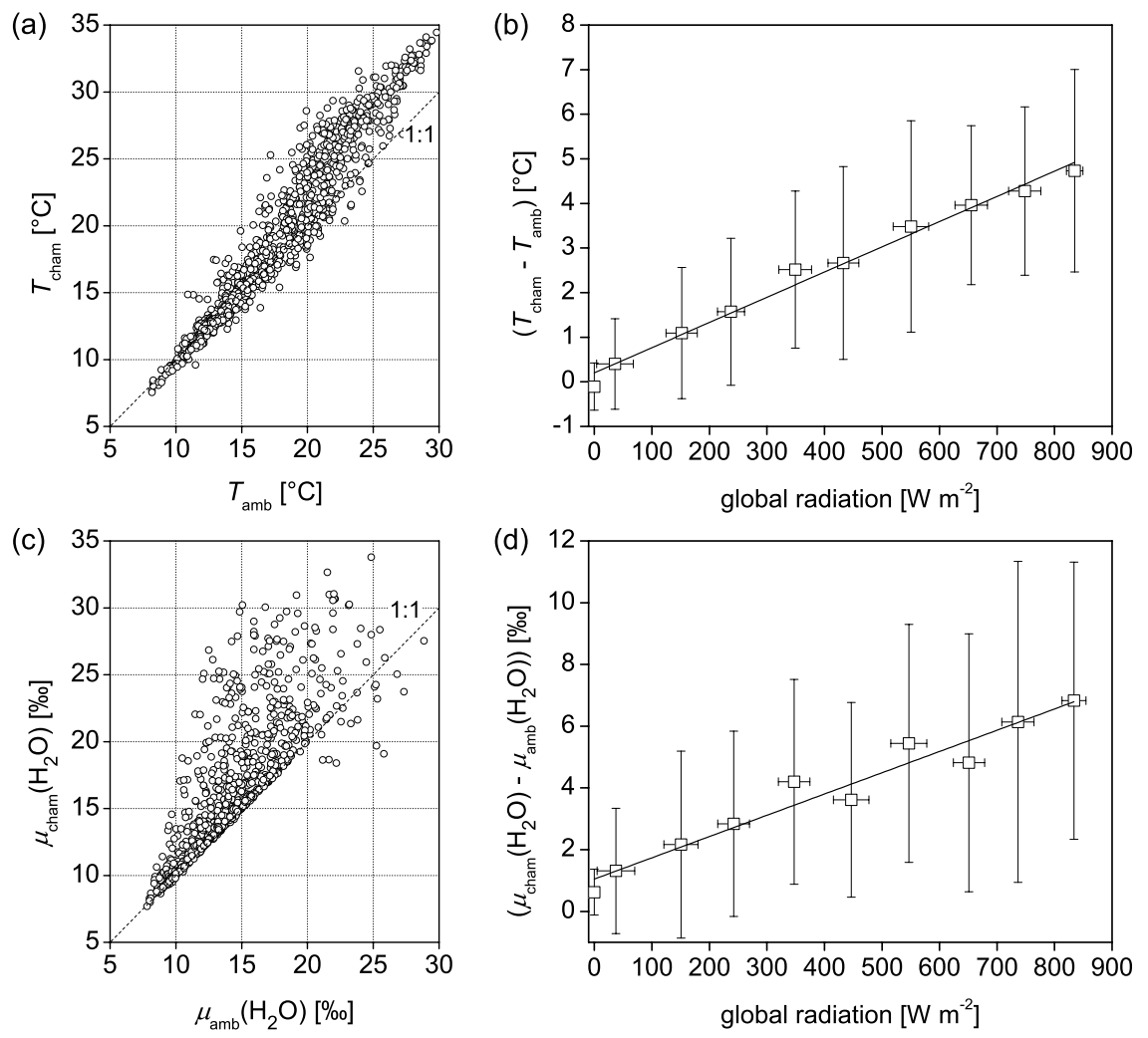

Fig. 11. Characterisation of chamber headspace conditions during the Rümlang field experiment (August/September 2004): (a) air temperature: $T_{\text {cham }}$ (in the closed chamber) vs. $T_{\mathrm{amb}}$ (in the open chamber); (b) average difference of air temperature $T_{\text {cham }}-T_{\mathrm{amb}}$ for classes of global radiation; linear fit (solid line): slope $=0.0057$, offset $=0.20, R^{2}=0.99$; (c) water vapour mixing ratio: $\mu_{\text {cham }}\left(\mathrm{H}_{2} \mathrm{O}\right)(\mathrm{chamber}$ headspace) vs. $\mu_{\mathrm{amb}}\left(\mathrm{H}_{2} \mathrm{O}\right)$ (chamber inlet); (d) averaged difference of water vapour mixing ratio $\mu_{\text {cham }}\left(\mathrm{H}_{2} \mathrm{O}\right)-\mu_{\mathrm{amb}}\left(\mathrm{H}_{2} \mathrm{O}\right)$ for classes of global radiation; linear fit ( solid line): slope $=0.0069$, offset $=1.05 ; R^{2}=0.94$.

measured as an omni-directional actinic UV radiation flux. However, during our field experiments, a $j\left(\mathrm{NO}_{2}\right)$ sensor (filter radiometer, Meteorologie Consult $\mathrm{GmbH}$, Königstein, Germany) was only available for a few weeks. Therefore, we tried to relate the $j\left(\mathrm{NO}_{2}\right)$ signal (inside and outside of the chamber) to the ambient global radiation, for which continuous measurements are available at our field sites. In a 5-week (18 May-26 June 2007) campaign at the Oensingen site, $j\left(\mathrm{NO}_{2}\right)$ was measured for 5 days within a closed dynamic chamber and for 30 days outside the chamber. Figure 12 shows the corresponding results as a function of the simultaneously measured global radiation $(G)$. For both, $j\left(\mathrm{NO}_{2}\right)$ inside and outside the chamber, a clearly non-linear relationship was observed that could be fitted well by 2 nd order polynomial functions (coefficients are given in the figure caption). The relationship for the closed chamber was generally used for the calculation of the net chemical sources of $\mathrm{NO}, \mathrm{NO}_{2}$ and $\mathrm{O}_{3}$ in Eqs. (8) and (9). For cases where measurements of ambient $j\left(\mathrm{NO}_{2}\right)$ are available, the transmissivity of the chamber walls for $j\left(\mathrm{NO}_{2}\right)$ related radiation (black dashed line in Fig. 12) was calculated as the ratio of both fitted polynomials. The transmissivity varies between 0.4 and 0.5 and can be described as a linear function of $G$ (see figure caption).

\subsection{Flux measurements on small grass plots}

As part of the Rümlang experiment the dynamic chamber system was installed on several small scale plots $(3 \times 6 \mathrm{~m})$, which were sown with different plant species and received different fertiliser amounts (see Sect. 2.3). Our main focus was the determination of $\mathrm{NO}, \mathrm{NO}_{2}$, and $\mathrm{O}_{3}$ exchange fluxes and their dependence on the management options. Figure 13 shows exemplary results of dynamic chamber flux measurements on two White clover plots and of the blank chamber operated in parallel for a one-week period (21-27 September 2004). The highly fertilised plot \#1 was characterised by an LAI of 3.3 at the time of the displayed measurements; the weakly fertilised plot \#2 was characterised by an LAI of 2.3. As indicated by the time series of ambient air temperature and global radiation observed at the site (Fig. 13f), there were fair weather 


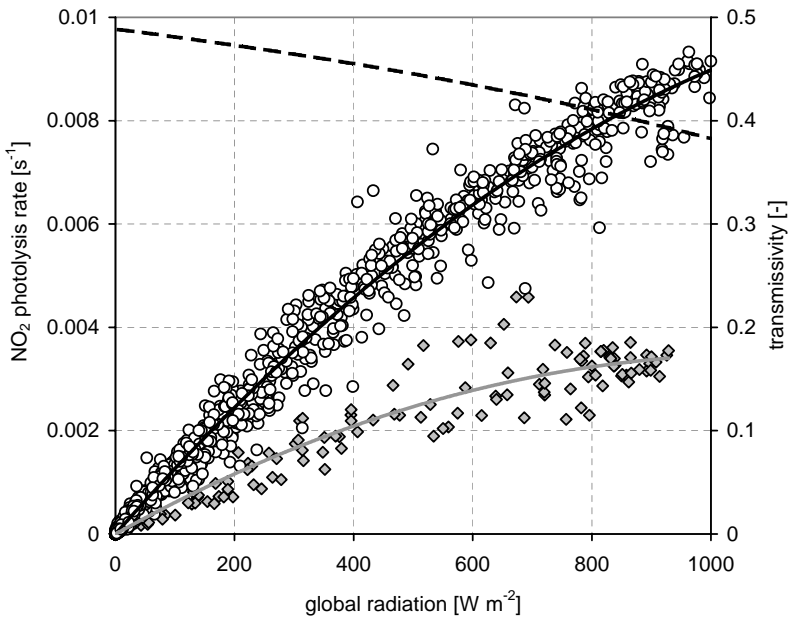

Fig. 12. $\mathrm{NO}_{2}$ photolysis rate $\left(j\left(\mathrm{NO}_{2}\right)\right)$ as a function of global radiation $(G)$ under ambient conditions (open circles) and inside the closed dynamic chamber (filled diamonds). In both cases, a 2nd order polynomial was fitted to the corresponding data points resulting in: $j\left(\mathrm{NO}_{2}\right)_{\mathrm{amb}}=-0.48 \times 10^{-9} G^{2}+1.31 \times 10^{-5} G$ (black solid line, $R^{2}=0.99, \quad n=1528$ ) and $j\left(\mathrm{NO}_{2}\right)_{\text {cham }}=-2.95 \times 10^{-9} G^{2}+6.40 \times 10^{-6} G$ (grey solid line, $\left.R^{2}=0.95, n=227\right)$. The photolysis related chamber transmissivity $\alpha=j\left(\mathrm{NO}_{2}\right)_{\text {cham }} / j\left(\mathrm{NO}_{2}\right)_{\mathrm{amb}}$ (black dashed line) was calculated as the ratio between the two polynomial fit curves and can be parameterised as a function of $G: \alpha=-10^{-4} G+0.49$.

conditions in the first half of the displayed period, followed by a significant decrease in both quantities. The observed $\mathrm{CO}_{2}$ exchange fluxes (representing the physiological activity of the vegetation) closely followed the course of the solar radiation for both clover plots (Fig. 13b). During daytime, plot \#1 showed slightly higher photosynthesis rates (larger negative $\mathrm{CO}_{2}$ fluxes) than plot \#2, which can be explained by the higher LAI of plot \#1. The $\mathrm{CO}_{2}$ fluxes of both plots were within a reasonable range for managed grassland ecosystems (see e.g. Ammann et al., 2007) indicating representative conditions for plant growth inside the chamber. The difference between the two plots concerning the NO flux was much more pronounced (Fig. 13c). While the NO fluxes of plot \#2 were not significantly different from zero, highly significant NO emissions were observed for plot \#1 with values mostly above $1 \mathrm{nmol} \mathrm{m}^{-2} \mathrm{~s}^{-1}$. While emission processes (e.g. for $\mathrm{NO}$ ) and the exchange of $\mathrm{CO}_{2}$ are supposed to be hardly affected by the modification of turbulence resistances of the dynamic chamber (see Sect. 2.1.2), this effect has to be considered for the purely diffusion-limited deposition processes for ozone and $\mathrm{NO}_{2}$. For these compounds the measured chamber flux $F_{\text {cham }}$ may deviate from the true ambient deposition flux (cf. Eq. 5), and thus the corresponding surface resistance $R_{\mathrm{c}}$ represents the more relevant result of the chamber measurements. Assuming a zero compensation point and neglecting $R_{\text {mix }}$,
Eq. (4) can be rearranged to:

$R_{\mathrm{c}}=\frac{\rho_{\mathrm{d}} \times \mu_{\mathrm{amb}}}{-F_{\text {cham }}}-R_{\text {purge }}-R_{\mathrm{b}}^{*}(\mathrm{LAI})$

with $F_{\text {cham }}$ determined according to Eq. (11). The resulting surface resistance values are plotted in Fig. 13d-e in their inverse form, i.e. as surface conductances $1 / R_{\mathrm{c}}\left(\mathrm{O}_{3}\right)$ and $1 / R_{\mathrm{c}}\left(\mathrm{NO}_{2}\right)$. This is graphically more suitable, because cases corresponding to zero fluxes appear as zero conductance values instead of very large or infinite resistances. Like for the photosynthetic $\mathrm{CO}_{2}$ uptake, the surface conductance for $\mathrm{O}_{3}$ and $\mathrm{NO}_{2}$ is generally lower for plot \#2 than for plot \#1. This observation can again be attributed to the higher LAI of plot \#1.

The blank chamber operated in the field experiment alongside with the regular sampling chambers serves as a check for the proper operation of the system and for the estimation of the effective uncertainty of the chamber fluxes. Ideally, the blank chamber flux is supposed to be zero, which is not always the case as shown in Fig. 13a-e. Statistical characteristics of the blank chamber fluxes measured during the Rümlang field campaign and corresponding results for methanol from the Oensingen experiment are listed in Table 3. The scatter of individual blank chamber fluxes is characterised by corresponding $10 \%$ and $90 \%$ quantiles ( $q_{10}$ and $q_{90}$ ) of the entire dataset. Except for NO, the range between $q_{10}$ and $q_{90}$ values is as high as $20 \%$ of the corresponding flux range observed by the regular chambers. The variability of the blank chamber fluxes is mainly caused by the non-stationarity of ambient trace gas concentrations during the individual measurement interval. In contrast, the overall means of the blank chamber fluxes are very small (Table 3). Yet, except for $\mathrm{NO}$ and $\mathrm{NO}_{2}$, they are significantly different from zero as indicated by the corresponding uncertainty range. A detailed assessment of the overall uncertainty of flux measurements with our dynamic chamber system will follow in Sect. 4.5.

\subsection{Comparison with eddy covariance measurements on the field scale}

A basic requirement of any chamber system to be applied on vegetated surfaces is to ensure a normal (unmodified) physiological behaviour of the enclosed plants. In order to investigate the influence of our dynamic chambers on diurnal plant physiological processes, we compared dynamic chamber derived $\mathrm{CO}_{2}$ and methanol fluxes with corresponding eddy covariance fluxes for a time period of six days (Fig. 14). The latter represent field scale measurements that integrate over a larger area of the investigated grassland field without affecting the vegetation and thus are supposed to represent average undisturbed fluxes. The gaps in the eddy covariance data result from failures of the corresponding trace gas analyser (e.g. 8 July for methanol) but also from methodological problems during calm night time conditions 
Table 3. Statistical parameters of blank chamber fluxes and range of observed regular chamber fluxes during the Rümlang field experiment (inorganic compounds) and the Oensingen field experiment (methanol). $q_{10}$ and $q_{90}$ denote the $10 \%$ and $90 \%$ quantiles of the entire dataset; $\mathrm{SE}$ denotes the standard error of the mean flux. The last column gives the respective flux ranges observed by the regular chambers during the field measurements.

\begin{tabular}{llccc}
\hline & & \multicolumn{2}{c}{ blank chamber fluxes } & reg. chamber fluxes \\
\hline Compound & units & $q_{10} \ldots q 90$ & mean $( \pm 2 \mathrm{SE})$ & observed range \\
\hline $\mathrm{CO}_{2}$ & $\mu \mathrm{mol} \mathrm{m}^{-2} \mathrm{~s}^{-1}$ & $-5.82 \ldots+4.16$ & $-0.47( \pm 0.31)$ & $-20 \ldots+10$ \\
$\mathrm{H}_{2} \mathrm{O}$ & $\mathrm{mmol} \mathrm{m}^{-2} \mathrm{~s}^{-1}$ & $-0.13 \ldots+0.74$ & $0.19( \pm 0.03)$ & $0 \ldots+8$ \\
$\mathrm{NO}$ & $\mathrm{nmol} \mathrm{m}^{-2} \mathrm{~s}^{-1}$ & $-0.14 \ldots+0.12$ & $0.009( \pm 0.018)$ & $0 \ldots+4$ \\
$\mathrm{NO}_{2}$ & $\mathrm{nmol} \mathrm{m}^{-2} \mathrm{~s}^{-1}$ & $-0.32 \ldots+0.35$ & $0.014( \pm 0.024)$ & $-2 \ldots 0$ \\
$\mathrm{O}_{3}$ & $\mathrm{nmol} \mathrm{m}^{-2} \mathrm{~s}^{-1}$ & $-1.50 \ldots+0.37$ & $-0.54( \pm 0.056)$ & $-5 \ldots 0$ \\
methanol & $\mathrm{nmol} \mathrm{m}^{-2} \mathrm{~s}^{-1}$ & $-0.56 \ldots+0.41$ & $-0.07( \pm 0.048)$ & $-1 \ldots+5$ \\
\hline
\end{tabular}

(cf. Ammann et al., 2007). The gaps in the chamber data are due to the rejection of data obtained under high non-stationarity of ambient mixing ratios (Sect. 2.3). Generally, an excellent agreement between chamber and eddy covariance fluxes was observed. The dynamic chamber system is able to detect the characteristic diurnal cycles with a sufficient temporal resolution. Both the $\mathrm{CO}_{2}$ and the methanol fluxes largely follow the course of the global radiation $(G)$. Even the short-term variability of $G$ is reflected in the chamber flux time series (e.g. on 7 July). With respect to the positive $\mathrm{CO}_{2}$ fluxes during night (representing soil and plant respiration) the dynamic chamber fluxes tend to be slightly lower compared to eddy covariance fluxes. This may be explained by the limited spatial representativeness of the two chambers and by a large small-scale variability for the soil respiration (compared to photosynthesis).

\section{Discussion}

\subsection{Requirements for dynamic chamber measurements}

The main requirements for any dynamic chamber measurement are

(a) minimal modification of the target trace gas exchange by the application of the chamber;

(b) mixing ratio differences between ambient and chamber air large enough that they can be detected by the available instruments for the encountered range of the target trace gas fluxes.

Beside these general requirements, several specific requirements have additionally been set for the applied system:

(c) applicability on low vegetation (in particular grassland);

(d) possibility for long-term unattended application (monitoring);

(e) surface flux measurements with high temporal resolution (approx. $1 \mathrm{~h}$ ); (f) parallel operation of several chambers to measure e.g. differences between manipulation plots or to assess the spatial heterogeneity of a site;

(g) simultaneous observation of surface exchange fluxes of various reactive and non-reactive trace gases.

The ability of our dynamic chamber system to meet these requirements will be discussed in comparison to other systems reported in the literature.

\subsection{Minimised modification by the chamber}

Fulfilment of requirements (a) and (c) by our chamber system implies a minimised disturbance of the plant physiological activity of the enclosed grassland vegetation. In order to achieve this target, the chamber frame and wall was constructed of highly transparent materials (particularly for photosynthetic active radiation, PAR). Together with our choice of a high purging air flow rate, they provide for a nearly undisturbed photosynthesis within the chambers as documented by the excellent agreement of $\mathrm{CO}_{2}$ fluxes measured by dynamic chambers and by eddy covariance (Fig. 14a). The slight reduction of PAR (about 14\%) due to the chamber walls is only of minor importance because the photosynthesis rate of grassland vegetation exhibits non-linear saturation effects already at low to medium PAR levels (Ammann et al., 2007). Thus the PAR reduction should only have an under-proportional effect on photosynthesis (mostly $<5 \%$ ). Furthermore, the good agreement of the methanol fluxes (Fig. 14b), which are supposed to be strongly controlled by stomatal conductance (see e.g. Harley et al., 2007), indicates the low impact of the (closed) chamber on the plant physiological activity of the grassland vegetation.

Fulfilment of requirement (a) does not necessarily imply that the environmental conditions (temperature, humidity, trace gas mixing ratios) in the chamber headspace must be very close to the ambient conditions outside the chamber. According to the resistance scheme displayed in Fig. 1 

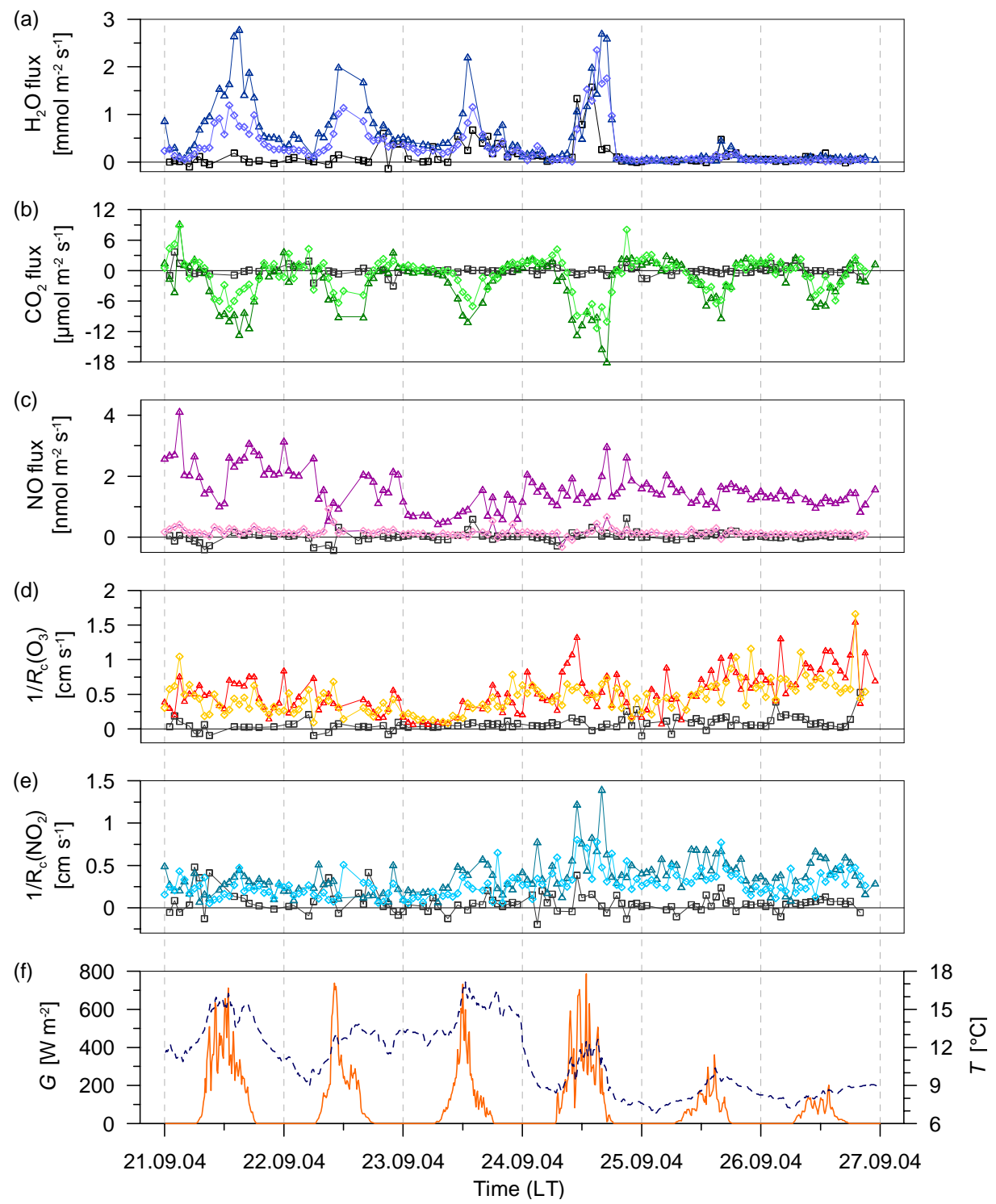

Fig. 13. Exemplary time series of (a) water vapour flux, (b) $\mathrm{CO}_{2}$ flux, (c) NO flux, (d) surface conductance for $\mathrm{O}_{3}$, (e) surface conductance for $\mathrm{NO}_{2}$, as observed at small scale plots $(3 \times 6 \mathrm{~m})$ with White clover monocultures at the Rümlang site. Chamber fluxes were measured on plot \#1 (triangles) with LAI=3.3 and high $\mathrm{N}$ fertilisation, plot \#2 (diamonds) with $\mathrm{LAI}=2.3$ and low $\mathrm{N}$ fertilisation, and by a blank chamber (squares) that was sealed against the ground with FEP film. (f) Time series of global radiation (orange solid line) and air temperature (blue dashed line) at $2 \mathrm{~m}$ height.

and the corresponding results in Sect. 3.2, the chamber headspace conditions represent an intermediate state within the resistance chain rather than ambient conditions. The exchange of chamber air by the purging air flow is generally slower than the mixing inside (enforced by the two mixing fans), and thus the properties of the equilibrated chamber air (especially the air temperature, see Fig. 11) are closer to leaf surface conditions than to ambient air conditions. Therefore, the chamber volume may be considered as an enhanced canopy or leaf boundary layer.
As discussed in Sect. 2.1.2, deposition fluxes are generally more affected by modified turbulence in the chamber than emission fluxes. However, the proposed resistance concept allows for a quantitative description and correction of this effect (cf. Eq. 5). Our resistance concept differs somewhat from that introduced by Ludwig (1994), where the purging process was not included (instead $\mu_{\text {cham }}$ was considered as a modified ambient mixing ratio). The advantage of the present concept is that it relates the modified chamber flux to the original undisturbed ambient mixing ratio. For deposition processes, the surface resistance $R_{\mathrm{c}}$ can be determined by 

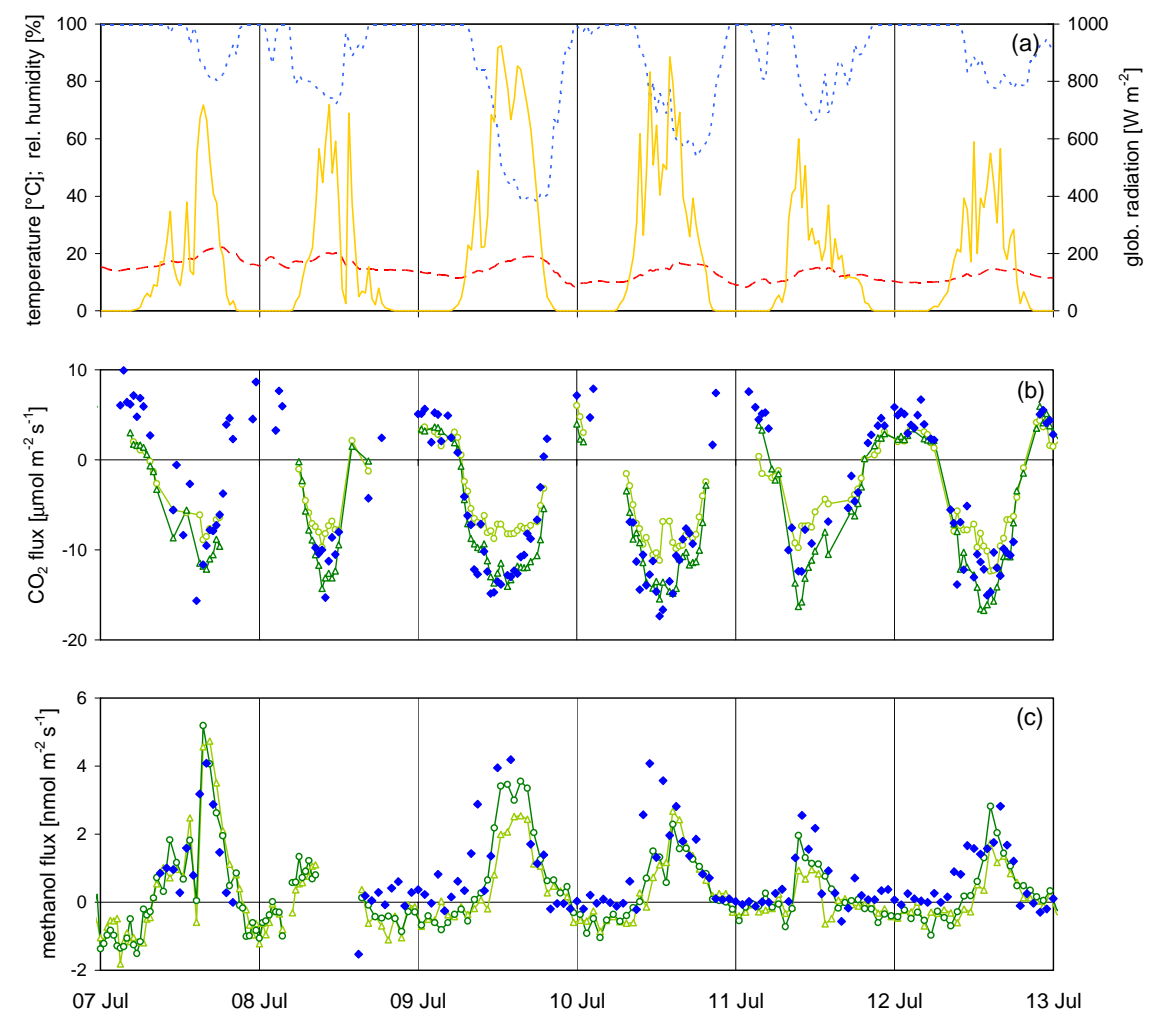

Fig. 14. Flux measurements and environmental conditions from 7 to 13 July 2004 at the Oensingen field site (intensively managed grassland): (a) air temperature (red dashed line), relative humidity (blue dotted line), and global radiation (yellow solid line); (b) and (c) $\mathrm{CO}_{2}$ and methanol surface exchange fluxes measured simultaneously by an eddy covariance system (blue filled diamonds) and two dynamic chambers (light and dark green open symbols).

Eq. (16) from the chamber flux measurements with known values of the chamber related resistances $R_{\mathrm{b}}^{*}$ and $R_{\text {purge }}$. Dry deposition models (Wesely and Hicks, 2000) usually need $R_{\mathrm{c}}$ values for each individual trace gas depending on the surface type and vegetation cover. Corresponding results from the Rümlang site (Fig. 13) show a higher conductance $1 / R_{\mathrm{c}}$ (i.e. lower $R_{\mathrm{c}}$ ) for $\mathrm{O}_{3}$ and $\mathrm{NO}_{2}$ on the plot with higher LAI. This observation can be attributed to the increasing number of stomata (proportional to the leaf surface) available for the uptake of trace gases. The generally lower conductance (higher $R_{\mathrm{c}}$ ) for $\mathrm{NO}_{2}$ compared to $\mathrm{O}_{3}$ may be an indication for the existence of an additional mesophyll resistance (cf. Wesely, 1989; Gut et al., 2002b) for the $\mathrm{NO}_{2}$ uptake within the leaf.

\subsection{Long-term applicability with high temporal resolution}

For long-term unattended application of the dynamic chamber system (requirement (d)), possible influences of the chambers on the enclosed vegetation was further minimised by using automated movable lids that are kept open outside the actual flux measurement intervals. In this way, the chambers remain open for about $80 \%$ of the entire duty time. Consequently, during our field experiments with this chamber system over full growing seasons (not shown) we could not identify any visual difference between the vegetation enclosed by the chambers and the surrounding vegetation, neither with respect to canopy height nor density. Operation failures of the chamber system were rare and reduced the data coverage by only $10-15 \%$. With the long open-state periods of the chambers also the exclusion of rainfall is small. For long-term measurements, a representative water supply to the enclosed soil area is crucial. In an earlier study with long-term fixed chambers without lids (Gut et al., 2002a; Kirkman et al., 2002), this problem was solved by installing a rain collecting funnel on top of each chamber (with similar cross section area), from which the rain was directed into the chambers. For a further optimisation of the present system, an on-line rain sensor signal might be used to force the chambers to remain open during significant rain events, as proposed by Butterbach-Bahl et al. (1997). It may be argued that the moving of the entire chamber (except for the soil frame) away from the investigated surface area (as e.g. used on forest floor by Pilegaard et al., 2003) would be better than just opening the chamber lid. Yet this solution is hardly practical 
Table 4. Characteristics of dynamic chamber measurements of nitric oxide and other trace gases on different ecosystems.

\begin{tabular}{|c|c|c|c|c|c|c|c|c|c|}
\hline Author & ecosystem & target gases $^{\mathrm{a}}$ & wall material ${ }^{\mathrm{b}}$ & $\begin{array}{l}\text { purging air } \\
\text { (incl. of } S_{\mathrm{gp}} \text { ) }\end{array}$ & $\begin{array}{l}\text { wall loss } \\
\text { determination }\end{array}$ & $\begin{array}{l}\text { internal } \\
\text { mixing }\end{array}$ & $\begin{array}{l}\text { closure time } \\
\left(\text { method }^{\mathrm{d}}\right)\end{array}$ & $\mathrm{V}[\mathrm{L}]$ & $\begin{array}{l}\tau_{\text {cham }} \\
{[\mathrm{mm}: \mathrm{ss}]}\end{array}$ \\
\hline Slemr and Seiler (1984) & grassland & $\mathrm{NO}, \mathrm{NO}_{2}$ & SS & ambient (no) & & no & $12 \min (\mathrm{M})$ & 18 & $00: 24$ \\
\hline Parrish et al. $(1987)^{\mathrm{c}}$ & grassland & $\mathrm{NO}, \mathrm{NO}_{2}$ & PA & zero-air (no) & blank chamber & no & $30-45 \min (\mathrm{M})$ & 28 & $05: 36$ \\
\hline Kaplan et al. (1988) & forest soil & NO & FEP* & ambient $\left(\right.$ yes $\left.^{\mathrm{e}}\right)$ & $\operatorname{yes}^{f}$ & yes & $?(\mathrm{M})$ & 7.2 & $24: 00$ \\
\hline Williams and Davidson (1993) & grassland & NO & PTFE* & zero-air (no) & & no & & $(30)$ & 07:30 \\
\hline Remde et al. (1993) & pasture & NO & SS/PA & ambient (yes) & blank chamber & yes & $4 \min (\mathrm{M})$ & 12.7 & $00: 17$ \\
\hline Skiba et al. (1993) & L. perenne & NO & $\mathrm{PA}$ & $\mathrm{O}_{3}$-free (no) & & yes & $?(\mathrm{M})$ & 570 & 07:07 \\
\hline Ludwig (1994) ${ }^{\mathrm{d}}$ & wheat & $\mathrm{NO}, \mathrm{NO}_{2}$ & PA & ambient (yes) & blank chamber & yes & $3 \min (\mathrm{A})$ & 42.6 & $00: 37$ \\
\hline Aneja et al. (1995) & agric. soils & NO & PTFE* & ambient (yes) & yes $^{f}$ & yes & $?(\mathrm{M})$ & 25 & $02: 47$ \\
\hline Yamulki (1995) & agric. soils & NO & PTFE* & $\mathrm{O}_{3}$-free (no) & & $?$ & $?(\mathrm{M})$ & 7.5 & $03: 45$ \\
\hline Meixner et al. (1997) & grassland & NO & PA & ambient (yes) & blank chamber & yes & $3 \min (\mathrm{A})$ & 25.7 & $00: 26$ \\
\hline Butterbach-Bahl et al. (1997) & forest soil & $\mathrm{NO}, \mathrm{NO}_{2}$ & PA & ambient (yes) & blank chamber & yes & $6 \min (\mathrm{A})$ & 37.5 & $00: 42$ \\
\hline Gut et al. (1999) & wheat & $\mathrm{NO}$ & PTFE* & ambient (yes) & blank chamber & yes & $3 \min (\mathrm{A})$ & 16 & $00: 10$ \\
\hline Pilegaard (1999) & forest soil & NO & PTFE* & ambient $\left(\mathrm{no}^{\mathrm{g}}\right)$ & $\mathrm{no}^{\mathrm{g}}$ & yes & $1 \mathrm{~h}(\mathrm{M})$ & 22.6 & $03: 14$ \\
\hline Roelle et al. (1999) & agric. soil & $\mathrm{NO}, \mathrm{NO}_{\mathrm{y}}$ & PTFE* & ambient $\left(\right.$ yes $^{f}$ ) & yes $^{f}$ & yes & $10 \mathrm{~h}(\mathrm{M})$ & 24 & $06: 00$ \\
\hline van Dijk and Duyzer (1999) & forest soil & $\mathrm{NO}$ & SS/PA & ambient (?) & & yes & $1 \mathrm{~h}(\mathrm{M})$ & 68 & $06: 48$ \\
\hline Roelle et al. (2001) & agric. soil & NO & PTFE* & ambient (?) & & yes & $10 \mathrm{~h}(\mathrm{M})$ & 24.1 & 06:01 \\
\hline Pilegaard (2001) & forest soil & $\mathrm{NO}, \mathrm{NO}_{2}, \mathrm{O}_{3}$ & PTFE & ambient (yes) & blank chamber & yes & $30 \min (\mathrm{A})$ & 12 & 01:20 \\
\hline Gut et al. $(2002 a, b)$ & forest soil & $\mathrm{NO}, \mathrm{NO}_{2}, \mathrm{O}_{3}, \mathrm{CO}_{2}$ & PA & ambient (yes) & blank chamber & yes & weeks $^{\mathrm{h}}(\mathrm{M})$ & 11.8 & $00: 25$ \\
\hline Kirkman et al. (2002) & pasture & $\mathrm{NO}, \mathrm{NO}_{2}, \mathrm{O}_{3}$ & PA & ambient (yes) & blank chamber & yes & weeks $^{\mathrm{h}}(\mathrm{M})$ & 11.8 & $00: 25$ \\
\hline Tilsner et al. (2003) & pasture & $\mathrm{NO}_{\mathrm{x}}$ & PTFE & zero-air (no) & & $?$ & $?(\mathrm{M})$ & 5.3 & $01: 24$ \\
\hline Kitzler et al. $(2006)^{\mathrm{h}}$ & forest soil & $\mathrm{NO}, \mathrm{NO}_{\mathrm{x}}$ & SS/PA & ambient (yes) & blank chamber & $?$ & $5 \min (A)$ & 3.3 & $03: 16$ \\
\hline ibid. & forest soil & NO & SS/PA & zero-air (no) & & $?$ & $5 \min (A)$ & 3.3 & $03: 16$ \\
\hline Horvath et al. (2006) & forest soil & NO & opaque & ambient (yes) & & $?$ & $10 \min (\mathrm{M})$ & 0.4 & $01: 13$ \\
\hline Maljanen et al. (2007) & pasture & NO & PVC & ambient (?) & & $?$ & $?(\mathrm{M})$ & 6.7 & $13: 24$ \\
\hline this study & grassland & $\begin{array}{l}\mathrm{NO}, \mathrm{NO}_{2}, \mathrm{O}_{3}, \mathrm{CO}_{2} \\
\mathrm{H}_{2} \mathrm{O} \text {, methanol }\end{array}$ & FEP & ambient (yes) & blank chamber & yes & $10-13 \min (\mathrm{A})$ & 40 & $00: 40$ \\
\hline
\end{tabular}

a only considering gases for which flux results (or deposition velocities/resistances) are reported;

${ }^{b}$ SS=stainless steel, PA=polyacrylics, PTFE, FEP, PFA=Teflon materials, PVC=polyvinyl chloride, *coating;

${ }^{\mathrm{c}} \mathrm{M}=$ manual closing, $\mathrm{A}=$ automated closing;

d see also Williams et al. (1987);

e see also Meixner (1994);

$\mathrm{f}$ empirical method after Kaplan (1988) using equilibration rate;

$\mathrm{g}$ negligible;

$\mathrm{h}$ continuous flushing, funnel on top for rain collection.

for dense and delicate grassland vegetation; it would likely be damaged irreversibly by frequent moving of the entire chambers.

While long-term applicability of the chamber system is necessary for monitoring entire seasonal cycles of trace gas fluxes and for deriving representative annual budgets, a high temporal resolution (requirement (e)) is essential for the detection and analysis of diurnal cycles as well as short term weather induced (e.g. rain, freezing/thawing) or management induced (e.g. fertilisation, harvest) emission pulses and variations. With the parallel operation of several chambers (requirement (f)) a one-hour resolution was achieved by a short flux measurement interval of only 10 to $12 \mathrm{~min}$ per individual chamber (Fig. 5). In the first four minutes of this interval, ambient air at the chamber inlet was sampled while the chamber was already closed and allowed to equilibrate. The experimental results and theoretical considerations in Sect. 3.1 give evidence that this time is always sufficient for an adequate equilibration (>98\%) of temperature and trace gas mixing ratios within the chamber under the chosen purging rate. This also applies to fast reacting gases like $\mathrm{O}_{3}$ and NO as found by the extensive simulation studies (Fig. 7).

In Table 4 the characteristics of our chamber system are compared to other dynamic chamber systems reported in literature for the measurement of soil NO emission from various ecosystems. Many of the chambers were operated manually and thus could be applied in the field only during either intensive short campaigns or with a very low time resolution in the order of weeks (often with long closure times). In addition, some of the chambers (applied to bare soil e.g. in forests) used opaque wall materials that are not suitable to study trace gas exchange of vegetation.

\subsection{Choice of purging flow rate}

For a given trace gas analyser, flux measurements by the dynamic chamber method are generally limited by the minimum detectable mixing ratio difference between chamber and ambient air (see Eq. 2 and requirement (b)). This mixing ratio difference is inversely proportional to the purging air flow rate $(Q)$. The relation is illustrated in Fig. 7a: the vertical span of each curve between the 
start point and the equilibrium state corresponds to the difference $\left(\mu_{\text {cham }}-\mu_{\mathrm{amb}}\right)$ for the respective $Q$ value. On the other hand, Fig. 7a also shows the strong reduction of the equilibration time with increasing $Q$ (in favour of requirement (e)). Another argument for a high purging flow are empirical findings by several authors, who report significant underestimation of soil emission fluxes of $\mathrm{NO}$ (Ludwig, 1994; Butterbach-Bahl et al., 1997; Gut et al., 1999) and of gaseous elemental mercury (Lindberg et al., 2002) under low purging rates. Thus the choice of the purging air flow rate is usually a compromise between different partly conflicting requirements (flux detection limit vs. time response and modification of turbulence resistances) for the chamber system.

The standard purging rate $Q=601 \mathrm{~min}^{-1}$ used in this study was chosen high enough to keep the mean residence time of the chamber air below one minute $\left(\tau_{\text {cham }}=41 \mathrm{~s}\right)$. This value is in the lower range of residence times reported in the literature (between $17 \mathrm{~s}$ and $24 \mathrm{~min}$, see Table 4). It guarantees a fast equilibration after closing the lid and allows an hourly measurement cycle with up to six chambers. A further increase of $Q$ was considered as unnecessary and would have made the flux detection more difficult (due to a smaller mixing ratio difference $\mu_{\mathrm{amb}}-$ $\left.\mu_{\text {cham }}\right)$. For other applications with different requirements and limitations, it may be adequate to choose a different purging flow. Aeschlimann et al. (2005), for example, used a slower purging flow rate during night than during day for imitating the diurnal variation of the aerodynamic resistances at ambient conditions. Such a feature could be easily implemented in the control program of our dynamic chamber system.

Although a certain pressure difference between outside and inside of the closed chamber is an inherent consequence of the purging flow, a too high flow rate in combination with small inlet/outlet orifices would cause a significant pressure difference that may influence the gas exchange with the soil (Gao and Yates, 1998). For our chamber system, the pressure difference was carefully checked by a sensitive differential pressure sensor (Honeywell DC2R5BDC4, range: $\pm 0.25 \mathrm{kPa}$ ) at various positions within the closed chamber in standard operation mode. It was found to be generally less than $2 \mathrm{~Pa}$.

\subsection{Significance of gas phase chemistry}

It has been pointed out in Sect. 2.1.3 that chamber flux measurements of reactive compounds like $\mathrm{NO}, \mathrm{NO}_{2}$, and $\mathrm{O}_{3}$ have to consider the chemical gas phase reactions inside the chamber. In order to illustrate the significance of gas phase chemistry, part of the chamber fluxes of $\mathrm{NO}, \mathrm{NO}_{2}$, and $\mathrm{O}_{3}$, corresponding to the results in Fig. 13, are compiled in Fig. 15 with a graphic indication of the respective gas phase reaction effect. A vertical line attached to each flux data point represents the contribution of the term $1 / A \times S_{\mathrm{gp}}$ in Eq. (11). Its absolute and relative magnitude depends on various factors. For the blank chamber, the effect is generally very small, which indicates that the ambient mixing ratios (which are very close to the respective blank chamber mixing ratios) for the three trace gases are already close to a photochemical equilibrium (i.e. the equilibrium between Eqs. 6 and 7). In the chamber on plot \#2 (small NO emission), this situation is only marginally modified by the deposition of $\mathrm{O}_{3}$ and $\mathrm{NO}_{2}$ leading to reduced mixing ratios in the chamber. However, for plot \#1 with strong NO emission, the addition of NO to the ambient and especially to the chamber air leads to an enhanced deviation from the photochemical equilibrium. Therefore the gas phase term can get quite large (up to $1 \mathrm{nmol} \mathrm{m}^{-2} \mathrm{~s}^{-1}$ ). Even for cases with a large absolute chemistry effect, its relative magnitude is generally less than $50 \%$ of the $\mathrm{NO}$ and $\mathrm{O}_{3}$ chamber fluxes. However, for the smaller $\mathrm{NO}_{2}$ fluxes, the chemical source term has a much larger relative effect. It can amount to more than two times the absolute value of the chamber flux meaning that an omission of the chemical source would even result in a wrong flux direction $\left(\mathrm{NO}_{2}\right.$ emission instead of deposition), as demonstrated in Fig. 15 for plot \#1.

These results show, that fast gas phase reactions of NO, $\mathrm{NO}_{2}$, and $\mathrm{O}_{3}$ have to be included in the calculation of each individual chamber flux. This necessitates the simultaneous measurement of all three trace gases, even if only one of them is of specific interest. Figure 15 also shows that the gas phase reaction term can differ significantly between chambers of neighbouring plots and in comparison to the blank chamber, because it depends on the local ambient mixing ratios and on the specific emission or deposition fluxes in the chamber. Thus it is in general not possible to quantify the contribution of chemical reactions based only on blank chamber measurements. For the investigation of soil NO emissions, gas phase reactions can be avoided by purging the chamber with zero air (see Table 4, e.g. Parrish et al., 1987; Williams and Davidson, 1993; Kitzler et al., 2006). However, in this way the exchange of other trace gases may be highly affected and can not be studied simultaneously. Furthermore, potential NO deposition fluxes can not be observed. They occur if the ambient NO mixing ratio exceeds the $\mathrm{NO}$ compensation mixing ratio in the soil (Conrad, 1994, 1996; Gut et al., 1999).

\subsection{Assessment of overall flux uncertainty}

The statistical uncertainty of flux measurements by the dynamic chamber method mainly depends on the uncertainty, with which the (average) trace gas mixing ratios of chamber and ambient air (and consequently their difference) can be measured. It is important to note in this context, that the observed mixing ratio difference in the field is often not limited by the precision of the trace gas analysers (Table 2), but rather by the temporal variability of the ambient concentration during a measurement interval (cf. 

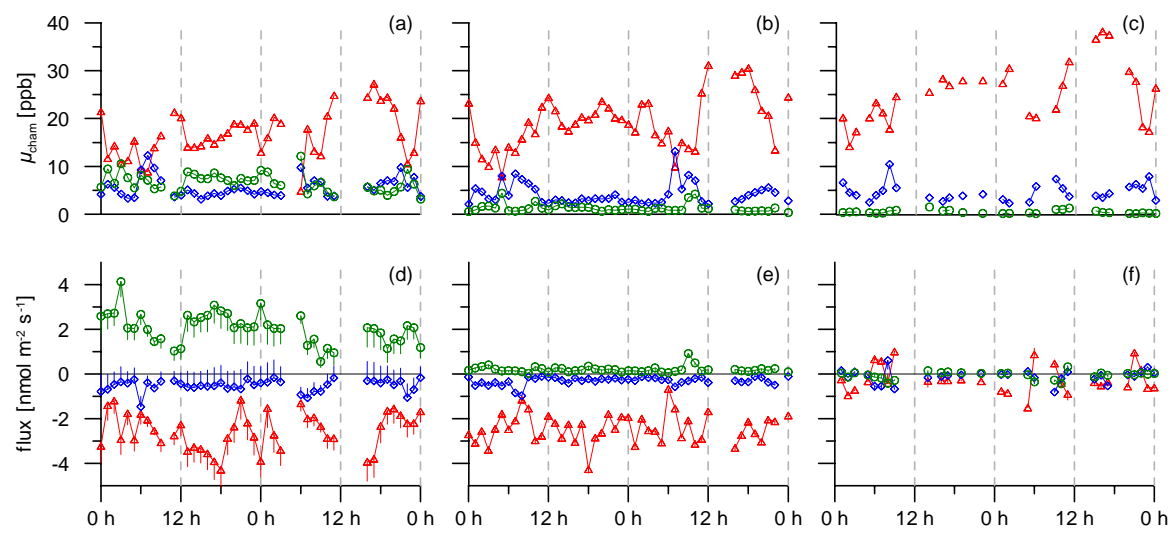

Fig. 15. Chamber mixing ratios and surface exchange fluxes of $\mathrm{NO}$ (green), $\mathrm{NO}_{2}$ (blue), and $\mathrm{O}_{3}$ (red) for part of the field experiment shown in Fig. 13: (a) and (d) clover plot \#1 with high fertilisation; (b) and (e) clover plot \#2 with low fertilisation; (c) and (f) blank chamber. The vertical lines on the flux data points in (d)-(f) indicate the contribution of the gas phase chemistry term $\left(1 / A \times S_{\mathrm{gp}}\right)$ to the chamber flux $F_{\text {cham }}$ in Eq. (11).

Sect. 2.3). In particular, reactive (short-lived) compounds like $\mathrm{O}_{3}, \mathrm{NO}, \mathrm{NO}_{2}$, and $\mathrm{VOC}$, which are the main target compounds for dynamic chamber measurements, may show large variability of ambient mixing ratio due to spatially varying sources (e.g. traffic). This effect is illustrated by the variability of blank chamber fluxes observed in the Rümlang field experiment (see Figs. 12 and 14). The random-like variability of the blank chamber fluxes is characterised by the range between the $10 \%$ and $90 \%$ quantiles in Table 3 . The same effect is expected to apply to the fluxes of the regular chambers. Therefore, the observed variability of the blank chamber fluxes represents a measure for the uncertainty (detection limit) of individual flux measurements. For some trace gases, a considerable relative uncertainty of individual chamber fluxes is observed (see e.g. $\mathrm{O}_{3}$ and $\mathrm{CO}_{2}$ in Table 3). Yet due to its random-like nature, it is efficiently reduced by any averaging procedure like temporal averaging or spatial averaging over parallel chambers.

Beside random-like errors, systematic errors may also add to the uncertainty of the fluxes. They can result from unknown or not adequately considered chemical reactions in the chamber headspace, for example the reaction of NO with the $\mathrm{HO}_{2}$ and $\mathrm{RO}_{2}$ radicals (see Aneja et al., 1995), which have not been measured here. Moreover, emission or deposition processes at the inner chamber walls (e.g. sorption processes or heterogeneous reactions at dirty or wet surfaces) may represent additional sources or sinks for target trace gases and thus may bias the intended biosphere-atmosphere exchange measurements. However, such systematic effects can also be checked by blank chamber measurements. For this purpose, the mean (temporally averaged) fluxes listed in Table 3 have to be considered. For $\mathrm{NO}$ and $\mathrm{NO}_{2}$, the mean blank chamber flux was not significantly different from zero and thus no systematic error needs to be taken into account. For ozone and methanol, however, significant negative biases of -0.54 and $-0.07 \mathrm{nmol} \mathrm{m}^{-2} \mathrm{~s}^{-1}$, respectively, were observed. They may be attributed to deposition to the chamber walls (see Meixner et al., 1997). The surface conductance $1 / R_{\mathrm{c}}\left(\mathrm{O}_{3}\right)$ in the blank chamber (Fig. 13d) tends to increase towards the end of the period, which can be explained by the rainy weather leading to wet inner wall surfaces. The latter effect is also reflected in the positive water vapour fluxes of the blank chamber indicating evaporation of collected rain or condensation water. A positive unambiguous attribution of systematic biases to a defined source/sink effect is generally difficult and has to be examined individually for each trace gas and chamber application. In the present case, the small but significant negative $\mathrm{CO}_{2}$ offset can hardly be explained by wall deposition. Alternatively, it might have been caused by analytical problems or by solution of $\mathrm{CO}_{2}$ in condensation water. Without a clear explanation, the systematic biases (mean blank chamber fluxes) in Table 3 have to be considered as systematic uncertainty of the chamber fluxes.

\section{Conclusions}

The presented laboratory tests and field applications show that the newly designed dynamic chamber system is well suited for surface exchange flux measurements of various reactive and non-reactive trace gases on grassland ecosystems. Beside the six trace gases presented here, our chamber system is supposed to be applicable for a large number of other compounds, e.g. for other VOC species that can be detected by the PTR-MS (cf. Davison et al., 2008; Rottenberger et al., 2008), for elemental mercury (Lindberg et al., 2002), or for sulphur compounds (Kuhn et al., 1999). For long-term automated applications of the chamber system on vegetated surfaces, the most important characteristic is the minimal disturbance of plant physiology and growth. 
This was checked by comparison of chamber measurements with independent eddy covariance measurements on the field scale. The fluxes of $\mathrm{CO}_{2}$ and methanol obtained with the two methods showed a very good agreement. This positive performance is ensured by transparent and inert wall materials, short measurement intervals and long phases with open lid (enabled by automated lid movement), high purging rate, and efficient mixing of the chamber air.

The long-term applicability of our dynamic chamber system can be combined with a high time resolution of the measurements in the order of $1 \mathrm{~h}$. This allows detailed observations of diurnal cycles as well as of strong but short emission pulses e.g. after rain events (Meixner et al., 1997), after cutting (Davison et al., 2008) or fertilisation (Bakwin et al., 1990). A variable number of individual chambers (e.g. to assess the spatial heterogeneity of a site, as done manually by Williams and Davidson, 1993; Maljanen et al., 2007), flexible controlling, variable operating parameters, variable number and type of analysers provide a high flexibility of the system and allow its application for numerous scientific investigations. During field experiments the system proved to be very robust and easy to maintain. All operational parameters are controlled automatically and logged continuously (together with basic environmental parameters like soil and air temperatures), which minimises manpower requirements.

The system is able to measure emission as well as deposition of trace gases. The necessary correction of deposition fluxes for the modified turbulence conditions can be achieved by consequent application of the described bulk resistance concept. As for all (dynamic) chamber systems, the chemical source/sink terms due to gas phase reactions need to be accounted for when measuring fluxes of reactive compounds like the $\mathrm{NO}-\mathrm{NO}_{2}-\mathrm{O}_{3}$ triad.

The presented dynamic chamber system is originally developed for the measurement of reactive trace gas exchange of grassland ecosystems. However, due to the flexible design it can also be applied to other ecosystems like bare soil and arable crops, on forest floors, or (without the soil frame) around individual branches or twigs (see Kuhn et al., 2002). Depending on the characteristics of the measurement site (root density, litter coverage, or structure of the soil), the present PVC soil collars may be omitted (cf. Gut et al., 2002a, b) or replaced by others, that are less deep or made of different material (e.g. stainless steel, cf. Bargsten et al., 2008). For vegetation higher than about $30 \mathrm{~cm}$, the chamber height can easily be extended by an additional cylinder module (similar to Bakwin et al., 1990; Suh et al., 2006). Finally, the chamber system may also be used for indoor applications with a controlled environment, e.g. in a climate control chamber (Brunner et al., 2007b), where the dynamic chambers can be fixed to planting pots directly.

\section{Appendix A}

\section{List of Symbols and Abbreviations}

All concentration and flux quantities are given in molar units. The concentration and flux units given in square brackets are used here for $\mathrm{O}_{3}, \mathrm{NO}, \mathrm{NO}_{2}$, and methanol. For other trace gases, other adequate prefixes are used: $\mathrm{ppm}$ $\equiv \mu \mathrm{mol} \mathrm{mol}^{-1}$ for $\mathrm{CO}_{2}$ and $\% o \equiv \mathrm{mmol} \mathrm{mol}^{-1}$ for $\mathrm{H}_{2} \mathrm{O}$.

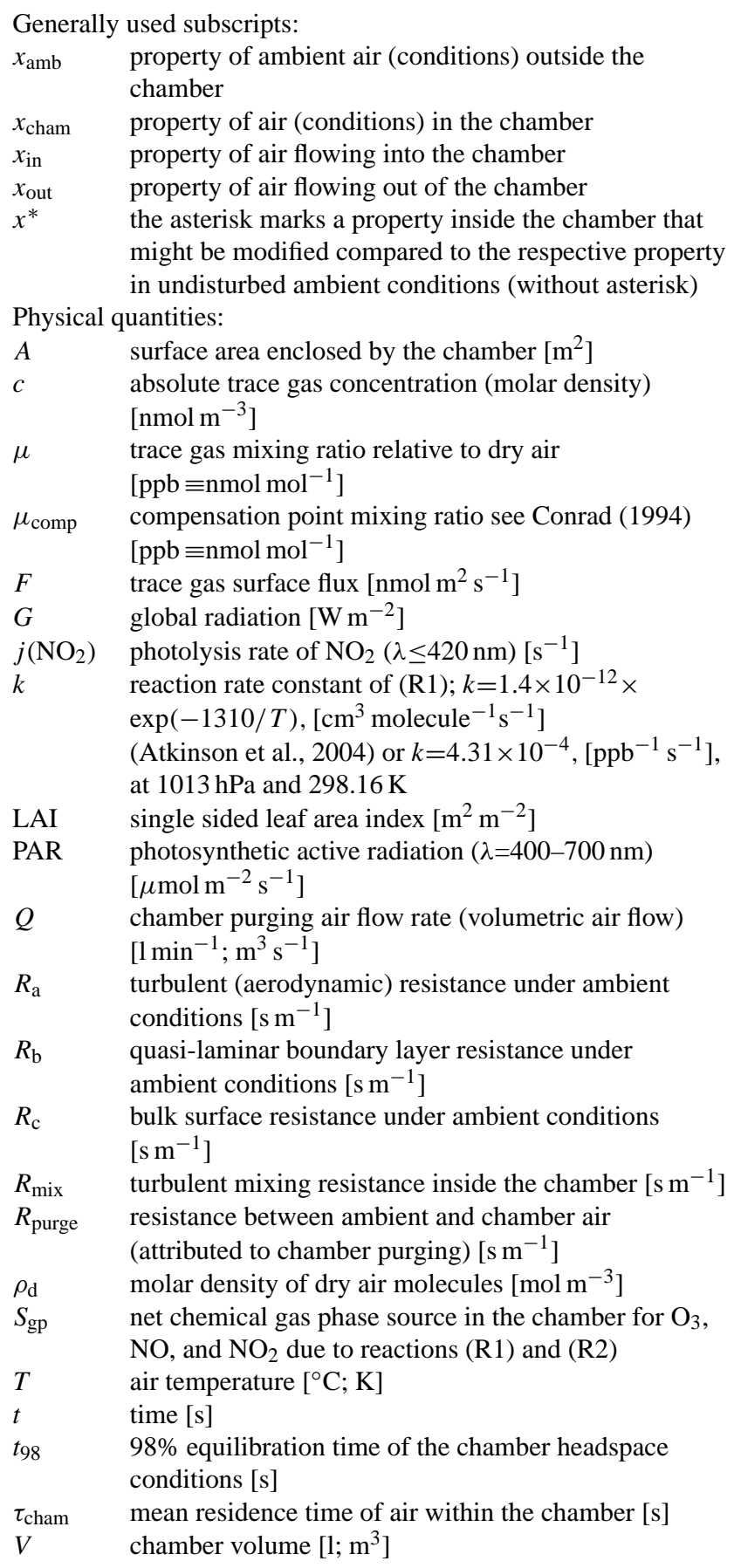

$x_{\text {ant }}$ 


\section{Appendix B}

\section{Derivation of dynamic chamber flux formula}

For any chamber system, the flux $F_{\text {cham }}$ of an inert trace gas (no chemical reaction with other air constituents or with the chamber walls) between the plant-soil system and the chamber air is determined by the mass balance of the enclosed volume $V$ (e.g. Gao and Yates, 1998):

$$
\begin{aligned}
& V \frac{d c_{\text {cham }}(t)}{d t}= \\
& \quad A \times F_{\text {cham }}+Q_{\text {in }} \times c_{\text {in }}(t)-Q_{\text {out }} \times c_{\text {out }}(t)
\end{aligned}
$$

where $c_{\text {cham }}$ is the average absolute concentration (molar density) of the target gas within the chamber volume $V$ and $A$ is the soil surface area enclosed by the chamber. $Q_{\text {in }}$ and $Q_{\text {out }}$ are the volumetric air flow rates and $c_{\text {in }}$ and $c_{\text {out }}$ the absolute trace gas concentrations of the incoming and outgoing air, respectively. While for a static chamber the air exchange is inhibited (making the $Q$-terms vanish), dynamic chambers are operated with a continuous purging of the chamber air leading to a steady-state equilibrium where the concentrations get time-independent and the time derivative in Eq. (B1) vanishes. Thus for a dynamic chamber in equilibrium conditions, the equation can be rearranged and reduced to:

$F_{\text {cham }}=\frac{1}{A}\left[Q_{\text {out }} \times c_{\text {out }}-Q_{\text {in }} \times c_{\text {in }}\right]$

The (standard) volumetric flow rates $Q_{\text {in }}$ and $Q_{\text {out }}$ are supposed to have similar values but are not fully equal in general. This is because of potential differences in temperature, pressure, and in the water vapour content (due to the formation of water vapour by evapotranspiration) of the inflowing and outflowing air. In order to account for these effects, the absolute concentration c has to be transferred to a mixing ratio $\mu$ relative to dry air:

$c=\mu \times \rho_{\mathrm{d}}$

Here $\rho_{\mathrm{d}}$ denotes the density of the dry air molecules (disregarding the water vapour molecules). Applying Eqs. (B2) to (B3) results in

$$
\begin{aligned}
F_{\text {cham }}= & \\
& \frac{1}{A}\left[Q_{\text {out }} \times \rho_{\text {d,out }} \times \mu_{\text {out }}-Q_{\text {in }} \times \rho_{\text {d,in }} \times \mu_{\text {in }}\right]
\end{aligned}
$$

$Q_{\text {out }} \times \rho_{\text {d,out }}$ and $Q_{\text {in }} \times \rho_{\text {d,in }}$ represent the flow of dry air molecules out of and into the chamber. According to mass conservation rules, these two terms have to be equal since there is no source or sink for dry air molecules within the chamber. Thus Eq. (B4) can be reduced to:

$F_{\text {cham }}=\frac{Q_{\text {in }}}{A} \times \rho_{\text {d,in }}\left[\mu_{\text {out }}-\mu_{\text {in }}\right]$
The deviation introduced e.g. by using $Q_{\text {out }}$ instead of $Q_{\text {in }}$ would be very small and purely relative (below $2 \%$ ). Therefore, for the sake of simplicity, the subscript "in" for $Q$ is omitted in the manuscript (see Eq. 1) and following, and the equation for the dynamic chamber flux of an inert trace gas finally results in:

$F_{\text {cham }}=\frac{Q}{A} \times \rho_{\mathrm{d}}\left[\mu_{\text {out }}-\mu_{\text {in }}\right]$

The important feature in this equation is comprised in the use of the mixing ratio relative to dry air $(\mu)$ instead of using absolute concentrations or a mixing ratio relative to the total wet air. The effect is analogous to the considerations by Webb et al. (1980) for micrometeorological flux measurements (see also Ammann, 1998). The normalisation to dry air is particularly important for trace gases with a high background concentration like e.g. $\mathrm{CO}_{2}$ and $\mathrm{N}_{2} \mathrm{O}$. Without this normalisation, a typical midday evapotranspiration rate $\left(\mathrm{H}_{2} \mathrm{O}\right.$ flux $)$ from vegetation of $10 \mathrm{mmol} \mathrm{m}^{-2} \mathrm{~s}^{-1}$ would result in a systematic underestimation of the $\mathrm{CO}_{2}$ flux by $-3.8 \mu \mathrm{mol} \mathrm{m}^{-2} \mathrm{~s}^{-1}$.

For the practical application of Eq. (B6) it should be noted that the air flow rate $Q$ is often measured by mass flow meters that yield the volumetric flow for "standard conditions" (temperature: $273 \mathrm{~K}$, pressure $1013 \mathrm{hPa}$ ). If these values are used, the dry air density has to be normalised to standard conditions as well.

Considering the origin of the inflowing air (ambient air near chamber inlet) and of the outflowing air (chamber volume), the mixing ratios are denoted accordingly: $\mu_{\mathrm{in}}=\mu_{\mathrm{amb}}$ and $\mu_{\text {out }}=\mu_{\text {cham. }}$. (see Fig. 1a and Sect. 2.1.1). For describing the temporal development of the equilibration process in the dynamic chamber after closing (before reaching the equilibrium state), one has to go back to the complete mass budget Eq. (B1). In order to formulate it in terms of mixing ratios, the derivation in Eqs. (B3-B6) have to be inserted back into Eq. (B1). This results in the following differential equation for the mixing ratio in the chamber:

$$
\begin{aligned}
& V \times \rho_{\mathrm{d}} \frac{d \mu_{\text {cham }}(t)}{d t}= \\
& \quad A \times F_{\text {cham }}-Q \times \rho_{\mathrm{d}}\left[\mu_{\text {cham }}-\mu_{\mathrm{amb}}\right]
\end{aligned}
$$

Here $\mu_{\mathrm{amb}}$ represents the constant (time-independent) trace gas mixing ratio of the inflowing ambient air and also the initial chamber concentration at $t=0$ before closing.

Acknowledgements. The authors thank the mechanical and electronics workshops of MPIC Mainz for technical advice and construction of the chambers and all controlling devices, M. Wiesmann for help with field installation and maintenance of the chamber system in Rümlang, J. Staehelin of ETH Zurich for borrowing us a $\mathrm{NO}_{2}$ photolysis radiometer, $\mathrm{M}$. Ermel for help with laboratory experiments. The measurements in Oensingen were financially supported by the Swiss National Science Foundation (Project COGAS, Nr. 200020-101636) and by the Swiss State Secretariat for Education and Research through grant Nr. SBF 
Nr. 03.0350-1 (Project CarboEurope-IP). The development of the chamber system and the field application in the Rümlang experiment was funded by the Max Planck Society.

The service charges for this open access publication have been covered by the Max Planck Society.

Edited by: T. Laurila

\section{References}

Aeschlimann, U., Nosberger, J., Edwards, P. J., Schneider, M. K., Richter, M., and Blum, $\mathrm{H}$.: Responses of net ecosystem $\mathrm{CO}_{2}$ exchange in managed grassland to long-term $\mathrm{CO}_{2}$ enrichment, $\mathrm{N}$ fertilization and plant species, Plant Cell Environ., 28, 823-833, 2005.

Ammann, C.: On the applicability of relaxed eddy accumulation and common methods for measuring trace gas surface fluxes, Swiss Federal Institute of Technology, Zurich, Switzerland, 239 pp., 1998.

Ammann, C., Flechard, C. R., Leifeld, J., Neftel, A., and Fuhrer, J.: The carbon budget of newly established temperate grassland depends on management intensity, Agr. Ecosys. Environ., 121, 5-20, 2007.

Aneja, V. P., Robarge, W. P., and Holbrook, B. D.: Measurements of Nitric-Oxide Flux from an Upper Coastal-Plain, North-Carolina Agricultural Soil, Atmos. Environ., 29, 3037-3042, 1995.

Atkinson, R., Baulch, D. L., Cox, R. A., Crowley, J. N., Hampson, R. F., Hynes, R. G., Jenkin, M. E., Rossi, M. J., and Troe, J.: Evaluated kinetic and photochemical data for atmospheric chemistry: Volume I - gas phase reactions of $\mathrm{O}_{\mathrm{x}}, \mathrm{HO}_{\mathrm{x}}, \mathrm{NO}_{\mathrm{x}}$ and $\mathrm{SO}_{\mathrm{x}}$ species, Atmos. Chem. Phys., 4, 1461-1738, 2004, http://www.atmos-chem-phys.net/4/1461/2004/.

Bakwin, P. S., Wofsy, S. C., Fan, S. M., Keller, M., Trumbore, S. E., and Dacosta, J. M.: Emission of Nitric-Oxide (NO) from Tropical Forest Soils and Exchange of NO between the Forest Canopy and Atmospheric Boundary-Layers, J. Geophys. Res.-Atmos., 95, 16755-16764, 1990.

Bargsten, A., Moravek, A., Huwe, B., Andreae, M. O., and Meixner, F. X.: Soil flux measurements of reactive and non-reactive trace gases in a mountainous region (Fichtelgebirge, Germany) by a dynamic chamber technique, Geophys. Res., Abstracts, 10, 06610, 2008.

Bassin, S., Volk, M., and Fuhrer, J.: Factors affecting the ozone sensitivity of temperate European grasslands: An overview, Environ. Pollut., 146, 678-691, 2007.

Brunner, A., Ammann, C., Neftel, A., and Spirig, C.: Methanol exchange between grassland and the atmosphere, Biogeosciences, 4, 395-410, 2007a, http://www.biogeosciences.net/4/395/2007/.

Brunner, A., Ammann, C., Jocher, M., Spirig, C., and Neftel, A.: Ozone triggers VOC emissions of grassland species, Geophys. Res., Abstracts, 9, 09784, 2007b.

Butcher, S. S., Charlson, R. J., Gordon, H. O., and Gordon, V. W.: Global Biogeochemical Cycles, International Geophysics Series, edited by: Dmowska, R., and Holton, J. R., Academic Press Inc., San Diego, 392 pp., 1992.
Butterbach-Bahl, K., Gasche, R., Breuer, L., and Papen, H.: Fluxes of $\mathrm{NO}$ and $\mathrm{N}_{2} \mathrm{O}$ from temperate forest soils: impact of forest type, $\mathrm{N}$ deposition and of liming on the $\mathrm{NO}$ and $\mathrm{N}_{2} \mathrm{O}$ emissions, Nutr. Cycl. Agroecosys., 48, 79-90, 1997.

Conrad, R.: Compensation concentration as critical variable for regulating the flux of trace gases between soil and atmosphere, Biogeochemistry, 27, 155-170, 1994.

Conrad, R.: Soil Microorganisms as controllers of atmospheric trace gases $\left(\mathrm{H}_{2}, \mathrm{CO}, \mathrm{CH}_{4}, \mathrm{~N}_{2} \mathrm{O}\right.$ and $\left.\mathrm{NO}\right)$, Microbiol. Rev., 60, 609-640, 1996.

Davison, B., Brunner, A., Ammann, C., Spirig, C., Jocher, M., and Neftel, A.: Cut-induced VOC emissions from agricultural grasslands, Plant Biol., 10, 76-85, 2008.

Galbally, I. E. and Roy, C. R.: Destruction of Ozone at the Earths Surface, Q. J. Roy. Meteorol. Soc., 106, 599-620, 1980.

Gao, F. and Yates, S. R.: Laboratory study of closed and dynamic flux chambers: Experimental results and implications for field application, J. Geophys. Res.-Atmos., 103, 26115-26125, 1998.

Gut, A., Neftel, A., Staffelbach, T., Riedo, M., and Lehmann, B. E.: Nitric oxide flux from soil during the growing season of wheat by continuous measurements of the NO soil-atmosphere concentration gradient: A process study, Plant Soil, 216, 165-180, 1999.

Gut, A., van Dijk, S. M., Scheibe, M., Rummel, U., Welling, M., Ammann, C., Meixner, F. X., Kirkman, G. A., Andreae, M. O., and Lehmann, B. E.: NO emission from an Amazonian rain forest soil: Continuous measurements of NO flux and soil concentration, J. Geophys. Res.-Atmos., 107, 8057, doi:10.1029/2001JD000521, 2002a.

Gut, A., Scheibe, M., Rottenberger, S., Rummel, U., Welling, M., Ammann, C., Kirkman, G. A., Kuhn, U., Meixner, F. X., Kesselmeier, J., Lehmann, B. E., Schmidt, W., Muller, E., and Piedade, M. T. F.: Exchange fluxes of $\mathrm{NO}_{2}$ and $\mathrm{O}_{3}$ at soil and leaf surfaces in an Amazonian rain forest, J. Geophys. Res.-Atmos., 107, 8060, doi:10.1029/2001JD000654, 2002b.

Harley, P., Greenberg, J., Niinemets, ., and Guenther, A.: Environmental controls over methanol emission from leaves, Biogeosciences, 4, 1083-1099, 2007,

http://www.biogeosciences.net/4/1083/2007/.

Herrmann, B., Jones, S. K., Fuhrer, J., Feller, U., and Neftel, A.: N budget and $\mathrm{NH} 3$ exchange of a grass/clover crop at two levels of N application, Plant Soil, 235, 243-252, 2001.

Hicks, B. B., Baldocchi, D. D., Meyers, T. P., Hosker, R. P., and Matt, D. R.: A Preliminary Multiple Resistance Routine for Deriving Dry Deposition Velocities from Measured Quantities, Water Air Soil Pollut., 36, 311-330, 1987.

Horst, T. W. and Weil, J. C.: How Far Is Far Enough - the Fetch Requirements for Micrometeorological Measurement of Surface Fluxes, J. Atmos. Ocean. Tech., 11, 1018-1025, 1994.

Horváth, L., Führer, E., and Lajtha, K.: Nitric oxide and nitrous oxide emission from Hungarian forest soils; link with atmospheric N-deposition, Biogeosciences Discuss., 2, 703-723, 2005 , http://www.biogeosciences-discuss.net/2/703/2005/.

Kaplan, W. A., Wofsy, S. C., Keller, M., and Dacosta, J. M.: Emission of NO and Deposition of O-3 in a Tropical Forest System, J. Geophys. Res.-Atmos., 93, 1389-1395, 1988.

Kesselmeier, J., Bode, K., Hofmann, U., Müller, H., Schäfer, L., Wolf, A., Ciccioli, P., Brancaleoni, E., Cecinato, A., Frattoni, M., 
Foster, P., Ferrari, C., Jacob, V., Fugit, J. L., Dutaur, L., Simon, V., and Torres, L.: Emission of short chained organic acids, aldehydes and monoterpenes from Quercus ilex L. and Pinus pinea $\mathrm{L}$. in relation to physiological activities, carbon budget and emission algorithms, Atmos. Environ., 31 (Suppl. 1), 119-133, 1997.

Kirkman, G. A., Gut, A., Ammann, C., Gatti, L. V., Cordova, A. M., Moura, M. A. L., Andreae, M. O., and Meixner, F. X.: Surface exchange of nitric oxide, nitrogen dioxide, and ozone at a cattle pasture in Rondonia, Brazil, J. Geophys. Res.-Atmos., 107, 8083, doi:10.1029/2001JD000523, 2002.

Kitzler, B., Zechmeister-Boltenstern, S., Holtermann, C., Skiba, U., and Butterbach-Bahl, K.: Nitrogen oxides emission from two beech forests subjected to different nitrogen loads, Biogeosciences, 3, 293-310, 2006,

http://www.biogeosciences.net/3/293/2006/.

Kuhn, U., Ammann, C., Wolf, A., Meixner, F. X., Andreae, M. O., and Kesselmeier, J.: Carbonyl sulfide exchange on an ecosystem scale: soil represents a dominant sink for atmospheric COS, Atmos. Environ., 33, 995-1008, 1999.

Kuhn, U., Rottenberger, S., Biesenthal, T., Ammann, C., Wolf, A., Schebeske, G., Oliva, S. T., Tavares, T. M., and Kesselmeier, J.: Exchange of short-chain monocarboxylic acids by vegetation at a remote tropical forest site in Amazonia, J. Geophys. Res.Atmos., 107, 8069, doi:10.1029/2000JD000303, 2002.

Lehmann, L.: Untersuchungen zu biogenen NO-Emissionen aus einem mitteleuropäischen Laubwaldboden, Institut für Geografie und Geoökologie, Universität Karlsruhe, Karlsruhe, Germany, 92 pp., 2002.

Lindberg, S. E., Zhang, H., Vette, A. F., Gustin, M. S., Barnett, M. O., and Kuiken, T.: Dynamic flux chamber measurement of gaseous mercury emission fluxes over soils: Part 2 - effect of flushing flow rate and verification of a two-resistance exchange interface simulation model, Atmos. Environ., 36, 847-859, 2002.

Livingston, G. P. and Hutchinson, G. L.: Enclosure-based measurements of trace gas exchange: applications and sources of error, in: Biogenic trace gases: measuring emission from soil and water, edited by: Matson, P. A. and Harriss, R. C., Blackwell Science Ltd., Oxford, UK, 1995.

Ludwig, J.: Untersuchungen zum Austausch von $\mathrm{NO}$ und $\mathrm{NO}_{2}$ zwischen Atmosphäre und Biosphäre, Fakultät für Biologie, Universität Bayreuth, Bayreuth, Germany, 1994.

Maljanen, M., Komulainen, V. M., Hytonen, J., Martikainen, P., and Laine, J.: Carbon dioxide, nitrous oxide and methane dynamics in boreal organic agricultural soils with different soil characteristics, Soil Biol. Biochem., 36, 1801-1808, 2004.

Maljanen, M., Martikkala, M., Koponen, H. T., Virkajarvi, P., and Martikainen, P. J.: Fluxes of nitrous oxide and nitric oxide from experimental excreta patches in boreal agricultural soil, Soil Biol. Biochem., 39, 914-920, 2007.

Meixner, F. X.: Surface exchange of odd nitrogen oxides, Nova Acta Leopoldiana, 70, 299-348, 1994.

Meixner, F. X., Fickinger, T., Marufu, L., Serca, D., Nathaus, F. J., Makina, E., Mukurumbira, L., and Andreae, M. O.: Preliminary results on nitric oxide emission from a southern African savanna ecosystem, Nutr. Cycl. Agroecosys., 48, 123-138, 1997.

Nussbaum, S. and Fuhrer, J.: Difference in ozone uptake in grassland species between open-top chambers and ambient air, Environ. Pollut., 109, 463-471, 2000.
Nyfeler, D., Huguenin-Elie, O., Suter, M., Frossard, E., Connolly, J., and Lüscher, A.: Transgressive overyielding in fertile agricultural grassland across a broad range of species proportions and nitrogen fertilisation, J. Appl. Ecol., in press, 2009.

Oke, T. R.: Boundary Layer Climates, Routlege, London and New York, 435 pp., 1987.

Parrish, D. D., Williams, E. J., Fahey, D. W., Liu, S. C., and Fehsenfeld, F. C.: Measurement of Nitrogen-Oxide Fluxes from Soils - Intercomparison of Enclosure and Gradient Measurement Techniques, J. Geophys. Res.-Atmos., 92, 2165-2171, 1987.

Pilegaard, K., Hummelshoj, P., and Jensen, N. O.: Nitric oxide emission from a Norway spruce forest floor, J. Geophys. Res.-Atmos., 104, 3433-3445, 1999.

Pilegaard, K.: Air-Soil Exchange of $\mathrm{NO}, \mathrm{NO}_{2}$ and $\mathrm{O}_{3}$ in Forests, Water Air Soil Pollut., Focus, 1, 79-88, 2001.

Pilegaard, K., Mikkelsen, T. N., Beier, C., Jensen, N. O., Ambus, P., and Ro-Poulsen, H.: Field measurements of atmosphere-biosphere interactions in a Danish beech forest, Boreal Environ. Res., 8, 315-333, 2003.

Pumpanen, J., Kolari, P., Ilvesniemi, H., Minkkinen, K., Vesala, T., Niinistö, S., Lohila, A., Larmola, T., Morero, M., Pihlatie, M., Janssens, I., Curiel Yuste, J., Grünzweig, J. M., Reth, S., Subke, J.-A., Savage, K., Kutsch, W., Ostreng, G., Ziegler, W., Anthoni, P., Lindroth, A., Hari, P.: Comparison of different chamber techniques for measuring soil $\mathrm{CO}_{2}$ efflux, Agr. Forest Meteorol., 123, 159-176, 2004.

Remde, A., Ludwig, J., Meixner, F. X., and Conrad, R.: A Study to Explain the Emission of Nitric-Oxide from a Marsh Soil, J. Atmos. Chem., 17, 249-275, 1993.

Roelle, P., Aneja, V. P., O'Connor, J., Robarge, W., Kim, D. S., and Levine, J. S.: Measurement of nitrogen oxide emissions from an agricultural soil with a dynamic chamber system, J. Geophys. Res.-Atmos., 104, 1609-1619, 1999.

Roelle, P. A., Aneja, V. P., Gay, B., Geron, C., and Pierce, T.: Biogenic nitric oxide emissions from cropland soils, Atmos. Environ., 35, 115-124, 2001.

Rottenberger, S., Kleiss, B., Kuhn, U., Wolf, A., Piedade, M. T. F., Junk, W., and Kesselmeier, J.: The effect of flooding on the exchange of the volatile $\mathrm{C}_{2}$-compounds ethanol, acetaldehyde and acetic acid between leaves of Amazonian floodplain tree species and the atmosphere, Biogeosciences, 5, 1085-1100, 2008 , http://www.biogeosciences.net/5/1085/2008/.

Skiba, U., Smith, K. A., and Fowler, D.: Nitrification and Denitrification as Sources of Nitric-Oxide and Nitrous-Oxide in a Sandy Loam Soil, Soil Biol. Biochem., 25, 1527-1536, 1993.

Slemr, F. and Seiler, W.: Field-Measurements of $\mathrm{NO}$ and $\mathrm{NO}_{2}$ Emissions from Fertilized and Unfertilized Soils, J. Atmos. Chem., 2, 1-24, 1984.

Suh, S. U., Chun, Y. M., Chae, N. Y., Kim, J., Lim, J. H., Yokozawa, M., Lee, M. S., and Lee, J. S.: A chamber system with automatic opening and closing for continuously measuring soil respiration based on an open-flow dynamic method, Ecol. Res., 21, 405414, 2006.

Tilsner, J., Wrage, N., Lauf, J., and Gebauer, G.: Emission of gaseous nitrogen oxides from an extensively managed grassland in NE Bavaria, Germany. I. Annual budgets of $\mathrm{N}_{2} \mathrm{O}$ and $\mathrm{NO}_{\mathrm{x}}$ emissions, Biogeochemistry, 63, 229-247, 2003.

van Dijk, S. M. and Duyzer, J. H.: Nitric oxide emissions from 
forest soils, J. Geophys. Res.-Atmos., 104, 15955-15961, 1999.

Warneck, P.: Chemistry of the Natural Atmosphere, 2 ed., International Geophysics Series, edited by: Dmowska, R. and Holton, J. R., Academic Press Inc., San Diego, USA, 927 pp., 2000.

Webb, E. K., Pearman, G. I., and Leuning, R.: Correction of Flux Measurements for Density Effects Due to Heat and Water-Vapor Transfer, Q. J. Roy. Meteorol. Soc., 106, 85-100, 1980.

Wesely, M. L.: Parameterization of Surface Resistances to Gaseous Dry Deposition in Regional-Scale Numerical-Models, Atmos. Environ., 23, 1293-1304, 1989.
Wesely, M. L. and Hicks, B. B.: A review of the current status of knowledge on dry deposition, Atmos. Environ., 34, 2261-2282, 2000.

Williams, E. J. and Davidson, E. A.: An Intercomparison of 2 Chamber Methods for the Determination of Emission of Nitric-Oxide from Soil, Atmos. Environ, Part a - General Topics, 27, 2107-2113, 1993.

Yamulki, S., Goulding, K. W. T., Webster, C. P., and Harrison, R. M.: Studies on $\mathrm{NO}$ and $\mathrm{N}_{2} \mathrm{O}$ Fluxes from a Wheat Field, Atmos. Environ., 29, 1627-1635, 1995. 